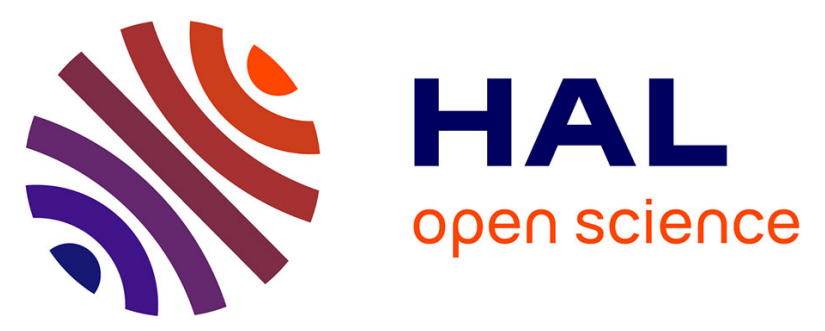

\title{
Self-determination trajectories during police officers' vocational training program: A growth mixture analysis
}

Nicolas Gillet, Alexandre J.S. Morin, Isabelle Huart, Dominique Odry, Séverine Chevalier, Hélène Coillot, Evelyne Fouquereau

\section{To cite this version:}

Nicolas Gillet, Alexandre J.S. Morin, Isabelle Huart, Dominique Odry, Séverine Chevalier, et al.. Self-determination trajectories during police officers' vocational training program: A growth mixture analysis. Journal of Vocational Behavior, 2018, 109, pp.27-43. 10.1016/j.jvb.2018.09.005 . hal02318920

\section{HAL Id: hal-02318920 \\ https://hal-univ-tours.archives-ouvertes.fr/hal-02318920}

Submitted on 28 Jun 2021

HAL is a multi-disciplinary open access archive for the deposit and dissemination of scientific research documents, whether they are published or not. The documents may come from teaching and research institutions in France or abroad, or from public or private research centers.
L'archive ouverte pluridisciplinaire HAL, est destinée au dépôt et à la diffusion de documents scientifiques de niveau recherche, publiés ou non, émanant des établissements d'enseignement et de recherche français ou étrangers, des laboratoires publics ou privés. 
Running Head: Self-Determination Trajectories

\title{
Self-Determination Trajectories during Police Officers' Vocational Training Program: A Growth Mixture Analysis
}

\author{
Nicolas Gillet ${ }^{1 *}$, Alexandre J. S. Morin ${ }^{2}$, Isabelle Huart ${ }^{13}$, Dominique Odry ${ }^{4}$, Séverine Chevalier ${ }^{1}$, \\ Hélène Coillot ${ }^{1}, \&$ Evelyne Fouquereau ${ }^{1}$ \\ ${ }^{1}$ Université de Tours, Tours, France \\ ${ }^{2}$ Concordia University, Montréal, Canada \\ ${ }^{3}$ Centre Régional de Formation de la Police Nationale, Saint Cyr sur Loire, France \\ ${ }^{4}$ Ministère de l'Intérieur, Paris, France
}

Since the first two authors (N.G. \& A.J.S.M.) contributed equally to the preparation of this paper, their order of appearance was determined at random: All should be considered first authors.

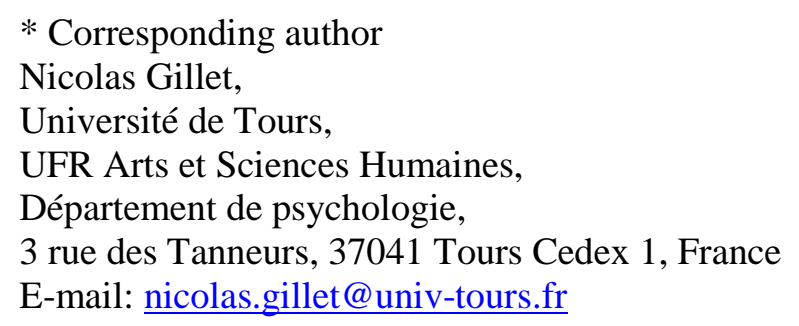

Funding: The second author was supported by a grant from the Social Science and Humanity Research Council of Canada (435-2018-0368) in the preparation of this manuscript.

This is the prepublication version of the following manuscript:

Gillet, N., Morin, A. J. S., Huart, I., Odry, D., Chevalier, S., Coillot, H., \& Fouquereau, E. (in press). Self-determination trajectories during police officers' vocational training program: A growth mixture analysis. Journal of Vocational Behavior. Early view. https://doi.org/ 10.1016/j.jvb.2018.09.005

(C) 2018. This paper is not the copy of record and may not exactly replicate the authoritative document published in Journal of Vocational Behavior.

\begin{abstract}
This study examines the evolution of police officers' global self-determination trajectories over the course of a vocational training program. We also examine the effects of mental load, work load, emotional load, and peer support on these trajectories. Moreover, this study documents the implications of these trajectories for a variety of outcomes (positive and negative affect, and performance). A sample of 1676 police officers completed all measures four times over the course of a vocational training. Longitudinal growth mixture analyses (GMA) revealed three distinct trajectories of self-determined motivation for the training (High, Moderate, and Low). Results showed that mental load increased the likelihood of membership into the High profile relative to the Moderate and Low profiles. Similarly, peer support increased the likelihood of membership into the High profile relative to the Moderate profile. In contrast, emotional load increased the likelihood of membership into the Moderate and High profiles relative to the Low profile. Finally, the High profile was associated with the highest levels of positive affect and performance, and the lowest levels of negative affect.
\end{abstract}

Keywords: Self-determination trajectories; Person-centered approach; Motivation; Police officers; Vocational training. 
The ability to transfer abilities acquired during training into the job is a ubiquitous but frequently unmet goal of training initiatives, amounting to billions of dollars lost annually, and resulting in masses of under-skilled workers who fail to apply training content to their job (Roberts, Rogers, Thomas, \& Spitzmueller, 2018). For instance, in 2017, organizations based in the United States spent $\$ 90.6$ billion and an average of 47.6 hours per employee on training and development (Training Magazine, 2017), without even considering vocational training costs occurring before entry into the workforce. Unfortunately, research suggests that only $10 \%$ to $13 \%$ of those expenditures actually resulted in changed trainee behavior once back on the job (Curry, Caplan, \& Knuppel, 1994). Among many, a key mechanism underpinning the failure of training programs is linked to trainees' lack of self-determined motivation during the training process (Bauer, Orvis, Ely, \& Surface, 2015). Indeed, numerous studies have shown that trainees characterized by high levels of self-determined motivation are more likely to perceive the learning content of their programs more constructively, to demonstrate higher levels of persistence in acquiring the skill set covered in the program, and to feel more accountable for ensuring their own mastery of the training objectives (Deci \& Ryan, 2000; Dysvik \& Kuvaas, 2008). For this reason, achieving a clear understanding of the processes involved in the evolution of trainees' selfdetermined motivation trajectories over the course of training appears to be central to our ability to devise strategies aiming to improve training success.

This consideration is particularly important in the context of vocational training programs which play a key role in ensuring that trainees are realistically prepared for entry into the workforce. Vocational training programs can also easily be adapted to target subsets of participants presenting less desirable motivational trajectories for preventive purposes. In particular, when this training focuses on a profession that can be as stressful and important as policing (Birch \& Herrington, 2011; Green, 2004), it becomes critical to maximize the preparation and motivation of upcoming officers. The present study seeks to contribute to a better understanding of training success through the identification of trainees' profiles characterized by distinct longitudinal trajectories of self-determined motivation over the course of a police vocational training program. The adoption of such a longitudinal perspective is, arguably, a key contribution of the present research. Indeed, and despite the fact that motivation is typically conceptualized as a dynamic process (e.g., Ryan \& Deci, 2017), the bulk of prior research conducted in the work or educational areas has been cross-sectional, or based on limited longitudinal designs precluding a clear understanding of motivation trajectories occurring at the individual level. In addition, we also consider the effects of mental load, work load, emotional load, and peer support during the course of vocational training as possible determinants of these self-determination trajectories, and investigate the associations between these trajectories and various outcomes (i.e., positive and negative affect, and objective performance).

The present study was also designed as a substantive-methodological synergy (Marsh \& Hau, 2007), seeking to illustrate how the reliance on innovative statistical procedures can help us to achieve a more refined understanding of individuals' self-determined motivation trajectories over the course of a vocational training program. As part of this synergistic effort, this study seeks to introduce organizational and vocational researchers to these procedures, and to demonstrate how these procedures can be used to enrich self-determination theory (SDT) research (Deci \& Ryan, 2000; Ryan \& Deci, 2017). More precisely, these procedures allowed us to achieve a more accurate measurement of trainees' global levels of self-determined motivation (via bifactor exploratory structural equation modeling - B-ESEM) coupled with the application of growth mixture analyses (GMA) to identify trainees characterized by distinct longitudinal trajectories.

\section{Self-Determination Theory}

Trainees' motivation represents the energizing/intensity, directing, and maintenance/persistence components of learning behavior in training contexts (Colquitt, LePine, \& Noe, 2000). According to SDT (Ryan \& Deci, 2017), individuals can be motivated for a variety of reasons. Intrinsic motivation refers to volitional engagement in an activity for the pleasure and satisfaction that it affords. Identified regulation refers to engagement in an activity that serves personally-endorsed values or objectives. Intrinsic motivation and identified regulation are conceptualized as autonomous forms of behavioral regulation. Introjected regulation refers to engagement in an activity driven by internal pressures, such as the avoidance of guilt and shame, or the pursuit of pride. External regulation refers to engagement in an activity that is controlled by external sources, such as rewards, punishments, or constraints. Introjected and external regulations are conceptualized as controlled forms of behavioral regulation. Finally, amotivation refers to the lack of 
motivation toward the target behavior.

SDT does not conceptualize these types of regulation as mutually exclusive but rather postulates that they can be placed on a continuum according to their level of self-determination. These various types of motivation are proposed to coexist within workers (Gillet, Becker, Lafrenière, Huart, \& Fouquereau, 2017; Howard, Gagné, Morin, \& Van den Broeck, 2016), and to follow an underlying continuum of selfdetermination ranging from intrinsic motivation to amotivation (Deci \& Ryan, 2000; Howard, Gagné, \& Bureau, 2017; Howard, Gagné, Morin, \& Forest, 2018). This continuum ranges from the more autonomous forms of regulation to the more controlled forms of regulation. Autonomous motivation characterizes engagement in activities driven by pleasure, volition, and choice, whereas controlled motivation characterizes activity engagement driven by internal or external pressures. More precisely, integrated regulation, identified regulation, introjected regulation, and external regulation fall in sequence between intrinsic motivation and amotivation on this continuum.

So far, research has generally supported the distinctive nature of the various types of behavioral regulation proposed by SDT, as well as their differential predictive validity in relation to a variety of outcome variables (Deci, Olafsen, \& Ryan, 2017; Gagné \& Deci, 2005; Guay, Ratelle, \& Chanal, 2008). However, the continuum hypothesis has recently been challenged. Relying on Rasch analyses, Chemolli and Gagné (2014) failed to find evidence supporting the idea that motivation ratings obtained in the work and education areas could be conceptualized according to a single dimension matching the continuum hypothesis. In contrast, parallel efforts have shown that the free estimation of cross-loadings between the behavioral regulation factors via ESEM (Asparouhov, Muthén, \& Morin, 2015; Morin, Marsh, \& Nagengast, 2013) resulted in the estimation of factor correlations more closely aligned with the hypothetical continuum structure (Guay, Morin, Litalien, Valois, \& Vallerand, 2015; Litalien, Guay, \& Morin, 2015). More recently, Howard et al. (2018; in the work area) and Litalien et al. (2017; in the education area) combined these two perspectives through the application of B-ESEM (Morin, Arens, \& Marsh, 2016) and provided a reliable, direct, and meaningful assessment of global levels of selfdetermined motivation, reflecting the SDT theoretical continuum. More specifically B-ESEM made it possible for them to identify a well-defined global factor reflecting the self-determination continuum (with factor loadings ranging from strongly positive for items tapping into more autonomous forms of motivation to moderately negative for amotivation items) co-existing with specific factors reflecting the variance uniquely attributable to each type of behavioral regulation.

Thus, despite the general recognition that a complete assessment of motivation should tap into the different types of behavioral regulation (Gillet, Becker et al., 2017), it has been demonstrated that individuals might experience motivation in a more holistic manner as a single overarching dimension. This global approach seems to be supported by the observation of high correlations among the different forms of motivation (Gillet, Morin, \& Reeve, 2017). Moreover, this global level of self-determination is the motivation facet displaying the strongest relation to a variety of predictors and outcome variables (e.g., psychological need satisfaction; achievement; dropout intentions; ill-being; Howard et al., 2018; Litalien et al., 2017). These results underscore the importance of considering global levels of selfdetermined work motivation in the context of research focusing on the emergence, development, and consequences of human motivation.

Importantly, these results match bulk of prior SDT research showing that individuals' levels of selfdetermination appear to be positively related to well-being and performance (Gillet, Fouquereau, Vallerand, Abraham, \& Colombat, 2018; Gillet, Vallerand, Lafrenière, \& Bureau, 2013) and negatively related to maladaptive outcomes (e.g., dropout intentions, burnout, negative affect; Fernet, Austin, \& Vallerand, 2012; Gillet, Gagné, Sauvagère, \& Fouquereau, 2013). These conclusions appear to hold across settings (e.g., sport, education, work), cultural contexts (Gillet, Fouquereau, Lafrenière, \& Huyghebaert, 2016; Jowett et al., 2017), and operationalization of motivation (either as a single score, as higher order autonomous and controlled scores, or as separate behavioral regulation dimensions; Fernet, Chanal, \& Guay, 2017; Howard et al., 2016; Koen, Klehe, \& van Vianen, 2015). This last observation supports the idea that the reliance on a single score, properly operationalized to reflect global levels of self-determined motivation, might represent a promisingly parsimonious approach to the study of motivation. In the present study, we adopt this new operationalization of self-determined motivation levels advocated by Howard et al. (2018) and Litalien et al. (2017) to consider the evolution of global levels self-determined motivation over the course of a vocational training program. More precisely, these global levels of self-determination can be considered to represent the extent to which trainees 
perceived their involvement into training activities to be self-determined (autonomously-driven with limited levels of external control) in nature.

\section{Self-Determined Motivation during Vocational Training \\ A Longitudinal Perspective.}

The bulk of research on work or academic motivation has relied on cross-sectional designs or on limited longitudinal designs (i.e., including only two time points), precluding a clear understanding of the developmental trajectories occurring at the individual level (Ployhart \& Vandenberg, 2010). More precisely, data collected across two times of measurement can be highly useful when the goal is to assess rank-order stability (stability in the relative position of individuals relative to one another, as assessed by correlations), the absolute magnitude of longitudinal change, cross-lagged relations among constructs, or even stability and change in motivational profiles (e.g., Gillet, Morin, \& Reeve, 2017). However, such data is not sufficient to achieve a proper understanding of intra-individual stability and change in the shape of motivation trajectories that best characterize specific individuals (Grimm, Ram, \& Estabrook, 2016). For this, more intensive longitudinal research (i.e., including three time points or more) is needed. In particular, more intensive longitudinal research appears to be critical for SDT, which defines motivation as a partly situational construct (e.g., Vallerand, 1997). In other words, motivation is seen as emerging in part from the changing characteristics of the specific life context to which a person is exposed rather than to be an inherently stable characteristic of that person.

In the training context, this dynamic nature of motivation is best reflected in Beier and Kanfer's (2009) model that depicts the evolution of trainees' motivation according to three stages. First, it begins with the motivation to enroll in the training program. Then, it follows by the motivation to participate in the learning and training activities during the program itself. Finally, it ends with the motivation to transfer the knowledge and skills acquired during training to their work environments. This three stage sequence makes it clear that motivation is expected to fluctuate to some extent during training. These fluctuations themselves may also vary from one person to another. As such, the ability to study how trainees' motivation evolves over time, and to be able to consider how this evolution differs across distinct subpopulations of individuals, would provide a rich window of opportunity to study the developmental mechanisms at play in the emergence of relations between motivation and a variety of important predictors and outcomes.

The GMA approach taken in this study is specifically designed to examine how self-determination trajectories of distinct profiles of upcoming police officers evolve over the course of their vocational training. It also aims to document how these distinct trajectories are related to various predictors and outcomes. More precisely, a first objective of the present study is to identify the most typical selfdetermination trajectories that characterize upcoming police officers over the course of their vocational training (9 months). The decision to focus on a sample of upcoming workers in a vocational training context is based on three distinct considerations. First, there is an almost complete lack of research on the precursors of work motivation. Given the intimate connection between vocational training and entry into the workforce that exists for police officers, many of which (at least in France) have prior experience of military or security work, vocational training appeared to be a natural entry point into the emergence of work motivation. Vocational training is typically when one's expectations regarding the anticipated nature of one's chosen profession are first challenged through a comparison with exposure to true job requirements, leading to potentially important changes in motivation levels.

Second, vocational training courses are more typically "self-determined" in nature when compared to the mandatory nature of daily job activities. This context is thus a potentially rich one to achieve a better understanding of the emergence and change in global self-determination levels at the initial stage of one's career. Third, learning and persistence in vocational training programs are critically important considerations for organizations worldwide. Indeed, vocational training is associated with multiple social, economic, and psychological consequences for the upcoming workers themselves as well as for organizations as a whole (Nilsson, 2010). In particular, the implications of such training programs become even more broadly relevant when the employing organization is the society itself, such as it is typically the case for police organizations. Among the key drivers of learning and persistence, workers' levels of self-determined motivation appear to represent a particularly important mechanism to consider (Deci et al., 2017). Yet, despite the importance of vocational training in terms of professional, social, and vocational achievement and success, self-determined motivation among trainees has received relatively little attention in prior longitudinal research. 
A Person-Centered Perspective on Longitudinal Trajectories.

Vocational training occupies a very unique position in research, being located at the border between educational and organizational research areas. For this reason, despite the lack of longitudinal research conducted in the organizational area focusing on workers' motivation, some guidance can be obtained from a consideration of the few studies conducted in the educational area among younger populations. Thus, longitudinal research conducted on sample of primary and secondary students generally tends to reveal decreasing levels of self-determined motivation (i.e., decreasing levels of autonomous motivation coupled with increasing levels of controlled motivation and amotivaiton) over time (e.g., Leroy \& Bressoux, 2016; Maulana, Opdenakker, \& Bosker, 2013). However, these levels might increase across the transition into higher education (Kyndt et al., 2015).

Importantly, all of these studies reported an important level of inter-individual heterogeneity. Part of this heterogeneity could be explained by the presence of subpopulations characterized by distinct longitudinal trajectories that may be important to identify for intervention purposes. Person-centered analyses, such as the longitudinal GMA approach adopted in this study, are specifically designed to assess how the self-determination trajectories of future police officers evolve over the course of their vocational training across distinct profiles of participants (Morin, 2016; Muthén, 2002).

Vocational training is a key component of upcoming employees' occupational socialization, defined as "a process by which an individual acquires the social knowledge and skills necessary to assume an organizational role" (Van Maanen \& Schein, 1979, p. 211). Interestingly, the research literature on occupational socialization explicitly recognizes that people are likely to follow very distinct longitudinal trajectories depending on the extent to which the socialization and training process matches or exceeds their expectations, or reveals unexpected aspects of work roles that are less desirable than initially anticipated (e.g., Boswell, Boudreau, Tichy, 2005; Solinger, Van Olffen, \& Hofmans, 2013; Weiss, 1978). For instance, some employees may display an initially cautious appraisal of the occupational requirements that become progressively integrated to their identities (referred to as the Learning to Love scenario). In contrast, other employees could experience increasing levels of disappointment following an initial level of exuberant enthusiasms (referred to as the Honeymoon-Hangover scenario). Finally, a final group of employees might encounter a reality that more closely matched their expectations (referred to as the Matching scenarios).

To our knowledge, a single study has relied on person-centered GMA to study motivation in the educational area. In this investigation of 410 students followed annually for two years, Nishimura and Sakurai (2017) identified two distinct longitudinal profiles. The first of those profiles characterized $22.2 \%$ of the students presenting decreasing levels of intrinsic motivation and identified regulation. The second profile characterized $77.8 \%$ of the students presenting increasing levels of external and introjected regulations. These two profiles apparently matched the aforementioned normative declines observed in self-determination levels (Leroy \& Bressoux, 2016; Maulana et al., 2013). Despite the lack of similar research on motivation trajectories conducted in the work area, Solinger et al. (2013) studied trajectories of affective commitment to their organization among a sample of 72 newly hired employees. Affective organizational commitment is a motivational construct referring to autonomously-driven force that binds employees to a course of action relevant to their organization (e.g., Meyer, Becker, \& Vandenberghe, 2004). Solinger et al.'s (2013) results, focusing on the first six months of employment, revealed trajectories corresponding to five onboarding socialization scenarios: Learning to Love (16.5\%), Honeymoon-Hangover (25\%), High Match (34.5\%), Moderate Match (12.5\%), and Low Match (11.5\%).

Unfortunately, despite their ground-breaking nature, these studies present a few critical limitations. First, GMA are computer-intensive and relatively demanding in terms of sample size. This may explain why these authors decided to rely on a suboptimal restricted parameterization of GMA (Diallo, Morin, \& Lu, 2016; Morin, Maïano et al., 2011), which may have impacted their results. Second, Nishimura and Sakurai's (2017) attempt to estimate distinct profiles of participants while simultaneously taking into consideration four highly correlated growth processes (rather than a single process at a time, or a global indicator of participants' levels of self-determined motivation). This might have limited their ability to identify more numerous profiles, particularly in light of the sample size requirements of GMA. Finally, and most importantly, Nishimura and Sakurai (2017) failed to demonstrate the construct validity of the extracted profiles through the demonstration of meaningful patterns of associations with theoretically significant covariates (Marsh, Lüdtke, Trautwein, \& Morin, 2009; Morin, Morizot, 
Boudrias, \& Madore, 2011). Although Solinger et al. (2013) did consider covariates related to the cognitive underpinning of these scenarios (person-organization fit, psychological contract breaches, and met expectations), it would have been interesting to also consider possible drivers of these trajectories, as well as likely outcomes. The present study addresses these limitations by adopting a less restricted GMA parameterization (see the analysis section for additional details). We also adopted a more parsimonious approach focusing on a single longitudinal process reflecting participants' global levels of self-determination. Finally, we addressed the construct validity of the extracted profiles using a much larger sample of participants.

Due to the rarity and limitations of prior research relying on a person-centered approach to identify motivation trajectories in the educational and work domains, it is difficult to formulate clear expectations regarding the nature of all profiles to be identified in the present study. However, based on the results obtained by Nishimura and Sakurai (2017) and Solinger et al. (2013), we propose the following hypotheses:

Hypothesis 1. Participants' self-determined motivation trajectories will be best represented by two to four profiles.

Hypothesis 2. At least some of those profiles will correspond to the Learning to Love (i.e., low levels followed by a progressive increase) or Honeymoon-Hangover (i.e., high levels followed by a progressive decrease) scenarios.

Hypothesis 3. A majority of participants will be characterized by profiles corresponding to the Matching (stable high, moderate, or low levels) scenarios.

\section{A Construct Validation Perspective}

The present study is the first to rely on the specific operationalization of participants' global levels of self-determination in the estimation of longitudinal trajectories. It is also the first to estimate such trajectories in a vocational training context. In person-centered research, best practice recommendations indicate the importance of documenting the criterion-related validity of the extracted trajectory profiles in relation to meaningful external covariates (e.g., Marsh et al., 2009; Morin, Morizot et al., 2011). To this end, a second objective of the present study is to adopt a construct-validation perspective in order to assess the effects of vocational training demands (mental load, work load, and emotional load) and resources (peer support) on these self-determination trajectories. We also investigated the associations between these trajectories and various outcomes (i.e., positive and negative affect, and objective performance). These covariates were selected based on their documented importance in the educational and work contexts, their relevance to SDT, and results from prior research on motivation conducted in the work or educational context (e.g., Gillet, Becker et al., 2017; Gillet, Vallerand et al., 2013).

\section{Vocational Training Demands and Resources.}

According to the job demands-resources model (Bakker \& Demerouti, 2007), a health impairment process is activated by excessive demands that lead to physical and psychological health problems. Demands refer to those aspects of an activity that require sustained physical and/or psychological effort and are therefore associated with physiological and/or psychological costs. In contrast, resources may help to enhance well-being and reduce ill-being as they contribute to achieving goals, reducing the costs associated with demands, and stimulating personal development. Demands and resources exert their influence through helping to build personal strengths (Xanthopoulou, Bakker, Demerouti, \& Schaufeli, 2007), professional development (Evers, van der Heijden, Kreijns, \& Vermeulen, 2016), equity (Hu, Schaufeli, \& Taris, 2013), recovery experiences (Kinnunen, Feldt, Siltaloppi, \& Sonnentag, 2011) or connectedness (Huynh, Xanthopoulou, \& Winefield, 2014). Despite the well-documented importance of demands and resources (e.g., Alarcon, 2011; Nahrgang, Morgeson, \& Hofmann, 2011), to the best of our knowledge, no person-centered research has examined the effects of demands (e.g., work load, mental load, emotional load) and resources (e.g., peer support) on self-determined motivation trajectories. However, prior variable-centered studies conducted in both the work and education contexts (e.g., Bartholomew et al., 2018; Fernet, Trépanier, Austin, Gagné, \& Forest; 2015; Trépanier, Forest, Fernet, \& Austin, 2015; Vujčić, Oerlemans, \& Bakker, 2017) suggest that demands and resources should predict participants' levels of self-determined motivation. For instance, Fernet et al. (2015) showed that work load was associated with lower levels of self-determined motivation. In contrast, social support is positively related to self-determined motivation (Gillet, Becker et al., 2017). Thus, higher demands should predict a greater likelihood of membership into the profiles characterized by lower levels and/or decreasing levels of global self-determination. In contrast, higher resources should predict a greater 
likelihood of membership into the profiles characterized by higher levels and/or increasing levels of global self-determination.

However, research has also shown that the effects of job demands on employees might differ according to their hindering or challenging nature (Cavanaugh, Boswell, Roehling, \& Boudreau, 2000; Crawford, LePine, \& Rich, 2010; LePine, Podsakoff, \& LePine, 2005). This distinction has also been found to be relevant to the prediction of self-determined work motivation (Fernet et al., 2015; Vujčić et al., 2017). More specifically, challenge demands are those that generate problem-focused coping activities contributing to the achievement of working goals. Hence, they create opportunities for development and growth, and in turn, lead to positive affective states and outcomes (Cavanaugh et al., 2000). In contrast, hindrance demands refer to obstacles that drain employees' energy. Hindrance demands lead employees to experience reduced control over their work environment and to rely on emotion-focused coping styles, in turn leading to a variety of negative affective states and outcomes (Van den Broeck, De Cuyper, De Witte, \& Vansteenkiste, 2010). Vujčić et al. (2017) showed that challenge demands were associated with higher levels of self-determined motivation. In contrast, hindrance demands were negatively related to self-determined motivation. These differential effects of challenge and hindrance demands on self-determination may be explained by the fact that challenges, contrary to hindrances, are positively related to need satisfaction (Olafsen \& Halvari, 2017).

In the present study, we rely on measures of mental load (i.e., a cognitive demand that primarily impinges on the brain processes involved in information processing such as working with a lot of precision), work load (i.e., trainees' perceptions of having too much work to do in the time available), and emotional load (i.e., the effort needed to deal with training inherent emotions) as joint indicators of training demands. Peer support (i.e., trainees' perceptions of social support that they receive from their colleagues) was also considered as an indicator of training resources (see Lequeurre, Gillet, Ragot, \& Fouquereau, 2013). Based on previous finding related to the job demands-resources model and to the challenge/hindrance distinction, we propose the following hypotheses:

Hypothesis 4. We expect higher perceptions of mental load (controlled for the effects of work load and emotional load) to predict a higher likelihood of membership into profiles characterized by higher and/or increasing levels of global self-determination.

Hypothesis 5. We expect higher perceptions of peer support to predict a higher likelihood of membership into profiles characterized by higher and/or increasing levels of global selfdetermination.

Hypothesis 6. We expect higher perceptions of work load (controlled for the effects of mental load and emotional load) and emotional load (controlled for the effects of work load and mental load) to predict a higher likelihood of membership into profiles characterized by lower and/or decreasing levels of global self-determination.

Outcomes of the Self-Determination Trajectories.

Finally, in order to better document the likely impact of membership into the various selfdetermination profiles on training success and participants' outcomes, we also assess the extent to which these profiles will be related to participants' levels of positive and negative affect at the end of the training. Moreover, we examine the associations between trainees' motivation profiles and their objective levels of achievement (as a performance outcome) at the end of the vocational training program. Consistent with SDT predictions (Deci \& Ryan, 2000), prior studies have supported the idea that higher levels of self-determination tended to be associated with higher levels of positive affect and lower levels of negative affect (Gillet, Becker et al., 2017; Vujčić et al., 2017), as well as with higher levels of performance (Trépanier et al., 2015; Valero, Hirschi, \& Strauss, 2015). In addition, positive affect was selected based on mounting research evidence supporting its key role in achievement (Gillet, Vallerand et al., 2013). Likewise, negative affect was retained based on its role in the prediction of turnover, which is in turn associated with important costs for organizations and educational systems (Kacmar, Andrews, Van Rooy, Steilberg, \& Cerrone, 2006). In addition, policing has been widely discussed as a stressful occupation and identified as one of the most demanding occupations worldwide (Duran, Woodhams, \& Bishopp, 2018). It thus appeared important to identify the factors potentially contributing to the development of future police officers' well- and ill-being. In line with these empirical results and theoretical considerations, we propose the following hypothesis:

Hypothesis 7. We expect the profiles characterized by higher levels and/or increasing levels of global self-determination to be associated with the most adaptive outcomes, and those characterized 
by lower and/or decreasing levels of global self-determination to be associated with the least desirable outcomes.

\section{Sample and Procedure}

\section{Method}

This study relies on a sample of 1676 participants (Mean age $=26.24 ; S D=3.83 ; 66.5 \%$ male) undergoing a 9-month full-time vocational training program to become police officers. Eighty-eight participants $(5.3 \%)$ had no previous diploma, 206 already had a previous vocational training certificate (12.3\%), 906 already had a previous high school diploma (54.1\%), 397 already had a previous university diploma (23.7\%), and 79 participants did not indicate their previous education level (4.7\%). Participation was voluntary and all future police officers enrolled in this program were invited to complete a self-reported questionnaire $5(n=868), 14(n=908), 25(n=843)$, and $41(n=604)$ weeks after the beginning of the training period. At each data collection point, members of the research team explained the purpose of the study to the participants. Then, trainees provided informed consent before completing a 15-minute questionnaire in the classroom. Participants were ensured that their responses would be kept confidential and would not impact their grades. They were also asked to provide a personal identification code to allow researchers to match their responses across data collection points.

\section{Measures}

Participants were first asked to indicate their age (in years), sex (coded 0 for males and 1 for females), and education level (0-no previous diploma to 3- University diploma). Then, they completed different scales assessing their motivation, perceptions of demands and resources, and affect.

Self-Determined Motivation. Participants completed Gagné et al.'s (2015) Multidimensional Work Motivation Scale, which was slightly adapted to refer to the vocational training context. This questionnaire includes 19 items, all rated on a 7-point scale ranging from 1 (does not correspond at all) to 7 (corresponds very strongly). It assesses six dimensions of motivation: (a) intrinsic motivation (3 items; e.g., "Because I have fun engaging in this training"; $\alpha_{t 1}=.85 ; \alpha_{t 2}=.87 ; \alpha_{t 3}=.88 ; \alpha_{t 4}=.85$ ), identified regulation ( 3 items; e.g., "Because putting efforts in this training has personal significance to me"; $\alpha_{\mathrm{t} 1}=.61 ; \alpha_{\mathrm{t} 2}=.64 ; \alpha_{\mathrm{t} 3}=.69 ; \alpha_{\mathrm{t} 4}=.70$ ), introjected regulation (4 items; e.g., "Because I have to prove to myself that I can"; $\alpha_{t 1}=.64 ; \alpha_{t 2}=.68 ; \alpha_{t 3}=.70 ; \alpha_{t 4}=.69$ ), external-social regulation (3 items; e.g., "Because others will respect me more"; $\alpha_{\mathrm{t} 1}=.70 ; \alpha_{\mathrm{t} 2}=.81 ; \alpha_{\mathrm{t} 3}=.84 ; \alpha_{\mathrm{t} 4}=.86$ ), external-material regulation ( 3 items; e.g., "Because others will reward me financially only if I put enough effort in this training"; $\alpha_{\mathrm{t} 1}=.48 ; \alpha_{\mathrm{t} 2}=.56 ; \alpha_{\mathrm{t} 3}=.61 ; \alpha_{\mathrm{t} 4}=.63$ ), and amotivation ( 3 items; e.g., "I do little because I don't think this training is worth putting efforts into"; $\alpha_{\mathrm{t} 1}=.87 ; \alpha_{\mathrm{t} 2}=.89 ; \alpha_{\mathrm{t} 3}=.91 ; \alpha_{\mathrm{t} 4}=.92$ ).

Demands and resources. Mental load (4 items; e.g., "During this training, do you have to give continuous attention to your work?"; $\left.\alpha_{\mathrm{t} 1}=.86 ; \alpha_{\mathrm{t} 2}=.88 ; \alpha_{\mathrm{t} 3}=.91 ; \alpha_{\mathrm{t} 4}=.88\right)$, work load (4 items, e.g., "During this training, do you have too much work to do?"; $\alpha_{\mathrm{t} 1}=.78 ; \alpha_{\mathrm{t} 2}=.80 ; \alpha_{\mathrm{t} 3}=.79 ; \alpha_{\mathrm{t} 4}=.82$ ), emotional load (4 items; e.g., "During this training, does your work demand a lot from you emotionally?"; $\alpha_{\mathrm{t} 1}=.75 ; \alpha_{\mathrm{t} 2}=.79 ; \alpha_{\mathrm{t} 3}=.80 ; \alpha_{\mathrm{t} 4}=.83$ ), and peer support (4 items; e.g., "Can you count on your colleagues when you encounter difficulties in this training?"; $\alpha_{t 1}=.89 ; \alpha_{t 2}=.91 ; \alpha_{t 3}=.95 ; \alpha_{t 4}=.93$ ) were measured with four subscales taken from a comprehensive measure developed and validated by Lequeurre et al. (2013). All items were rated on a 7-point response scale ranging from 1 (never) to 7 (always) and referring to the training context.

Positive and negative affect. Participants' levels of positive (5 items; e.g., "calm"; $\alpha_{\mathrm{t} 1}=.72 ; \alpha_{\mathrm{t} 2}=$ $.76 ; \alpha_{\mathrm{t} 3}=.81 ; \alpha_{\mathrm{t} 4}=.83$ ) and negative (5 items; e.g., "depressed"; $\alpha_{\mathrm{t} 1}=.78 ; \alpha_{\mathrm{t} 2}=.80 ; \alpha_{\mathrm{t} 3}=.83 ; \alpha_{\mathrm{t} 4}=.82$ ) affect during training were assessed with two relevant subscales from the Job-related Affective Wellbeing Scale (JAWS; Van Katwyk, Fox, Spector, \& Kelloway, 2000). Responses were provided on a 5point scale (1- never to 5- always).

Performance. At the end of the training, official grade transcripts were received from the administrative office of the National Police Academy and used as an objective performance outcome. We rely here on the final global grade obtained at the term of the vocational training program (ranging between 847 and 1300 with $M=1125.6$ and $S D=72.27$ ). This is the result of the compilation of all assessments (over 20 of them) completed by the trainees over the course of the program. They include both theoretical exams (e.g., principles of identity control, intervention in a context of family violence) and practical trials (e.g., athletic, shooting).

\section{Model Estimation and Missing Data}

\section{Analyses}


All models were estimated using Mplus 8.0's (Muthén \& Muthén, 2017) robust Maximum Likelihood (MLR) estimator. These models were estimated with Full Information Maximum Likelihood (FIML; Enders, 2010) procedures to account for the relatively limited amount of missing responses at the item level for participants who completed each time point (.12\% to 5.63\%). FIML also allowed us to estimate all longitudinal models using the data from all respondents who completed at least one wave of data rather than using a listwise deletion strategy focusing only on those having answered all, or a subset, of time waves (Enders, 2010; Graham, 2009). In total, 1676 participants provided a total of 3223 time-specific ratings ( $M=1.92$ time-specific ratings per participants).

\section{Preliminary Analyses}

Rather than using scale scores (the mean or sum of the items) to estimate the trajectories and their relations with predictors and outcomes, factor scores from preliminary measurement models were used for the analyses. For the motivation and predictors measures, these factor scores were estimated in standardized units at Time 1 with $M=0$ and $S D=1$, with the remaining time points estimated as deviations from Time 1 in $S D$ units. For the outcome measures, we selected Time 4 as the referent time point to set $M=0$ and $S D=1$. The measurement models for the motivation measure were estimated using B-ESEM (Morin, Arens, \& Marsh, 2016; Morin, Boudrias et al., 2016, 2017). This decision is based on recent studies showing that B-ESEM is naturally suited to measures of work (Howard et al., 2018), academic (Litalien et al., 2017), and sport (Gunnel \& Gaudreau, 2015) motivation based on SDT (Deci \& Ryan, 2000). These studies showed that B-ESEM provides a way to obtain a direct and precise estimate of the global continuum of self-determination proposed by SDT to underlie all motivation ratings (i.e., the global "quantity" of self-determination). This global levels of self-determination is used here to estimate participants' trajectories. To ensure the comparability of measurement across time waves, factors scores were saved from longitudinally invariant measurement models (Millsap, 2011). Although factor scores do not explicitly control for measurement errors the way latent variables do, they provide a partial control for them (Skrondal \& Laake, 2001) by giving more weight to more reliable items (for additional discussions of factor scores, see Morin, Boudrias et al., 2016, 2017; Morin, Meyer, Creusier, \& Biétry, 2016). Details on these measurement models and their longitudinal invariance are reported in Appendix 1 of the online supplements. Readers interested in learning more about the estimation of B-ESEM models are referred to Morin, Arens, and Marsh (2016) introduction to these models, which comes with an extensive set of annotated syntax for their estimation. The correlations between all variables (i.e., the factor scores saved from these final measurement models and the single item measure of performance) are reported in Table 1.

\section{Growth Mixture Analyses (GMA)}

Quadratic GMA models including one to eight latent trajectories of global self-determination were estimated and compared. GMA are built from latent curve models (Bollen \& Curran, 2006) to identify subgroups of participants following distinct longitudinal trajectories (Grimm et al., 2016; Morin, Maïano et al., 2011). Quadratic GMA summarize a series of repeated measures by the estimation of random intercept, linear slopes, and quadratic slope factors reflecting, respectively, the initial level of the growth trajectories, the average rate of change over time, and the presence of curvilinearity in the trajectories. This curvilinear component allows for the detection of u-shape, or inverted u-shape trajectories. Quadratic GMA models are very flexible, allowing for the estimation of trajectories that can be (i) stable (when the linear and quadratic slopes are close to zero and non-significant), (ii) linear (increasing or decreasing in a linear manner, when the quadratic slope is close to zero and non-significant), or (iii) curvilinear (u-shape or inverted $\mathrm{u}$-shape trajectories). Time codes on the slope factors were set to 0 at Time 1 (to allow the intercept factor to reflect global self-determination levels at the initial time point), 2 at Time 2, 5 at Time 3, and 9 at Time 4 to reflect the passage of time (in months, rounded to the closest unit). These time codes were squared on the quadratic slope factor. To avoid converging on a local maxima, all models were estimated using 10,000 random sets of start values, 1,000 iterations, and 500 solutions for final stage optimization (Hipp \& Bauer, 2006). A more technical presentation of GMA is provided in Appendix 2 of the online supplements. Readers interested in learning more about the estimation of GMA models are referred to Morin and Litalien (2018) recent introductory chapter, which comes with an extensive set of annotated input files.

Current statistical recommendations are that GMA should, whenever possible, be estimated while allowing all models parameters (intercept and slopes means, intercept and slopes variances and covariances, and time-specific residuals) to be freely estimated in all profiles (Diallo et al., 2016; Morin, 
Maïano et al., 2011). However, this recommendation comes with the recognition that this free estimation of all parameters is not always possible due to the tendency of these more complex models to converge on improper solutions, or not to converge at all (Diallo et al., 2016). This was the case in the present study. In such situations, the recommendation is to implement equality constraints across profiles on specific parameters to achieve a more parsimonious representation (Diallo et al., 2016). Here, we set the latent variance-covariance matrix to be invariant across profiles, but allowed the time-specific residuals to be freely estimated across profiles.

Predictors and Outcomes of Profile Membership. Once the optimal number of profiles has been selected, relations between these profiles and a series of predictors and outcomes were investigated. These predictors and outcomes were directly included in the model (which is recognized as the most efficient way to assess covariates effects; Meyer \& Morin, 2016; Morin \& Litalien, 2018) using the start values from the final retained unconditional solution to ensure that the inclusion of these covariates did not change the nature of the profiles (Diallo, Morin, \& Lu, 2017; Marsh et al., 2009; Morin, Meyer et al., 2016). For analyses of predictors, a series of alternative models was contrasted, following recommendations from Diallo et al. (2017) implemented in applied research by Morin and colleagues (Morin, Rodriguez, Fallu, Maïano, \& Janosz, 2012; Morin, Maïano et al., 2011, 2013).

We first considered models including potential demographic controls assessed at Time 1 (age, sex, and education level) to verify the need to incorporate these controls as additional predictors in further models. First, a null effects model was estimated in which the effects of the controls on the probability of membership in all profiles, as well as on the growth factors, were constrained to be zero. Second, a model was estimated in which the controls were allowed to predict profile membership through a multinomial logistic regression. Additional models were then estimated in which predictors were also allowed to influence (via multiple regression) within-profile variation in the intercepts and slopes of the trajectories, and in which these effects were allowed to vary across profiles. These tests aimed to determine which, if any, of these control variables needed to be retained for the subsequent models.

In a second series of models, the same sequence was repeated to assess the effects of the predictors (mental load, work load, emotional load, and peer support). To ensure a temporal ordering of the predictors relative to the predicted variables (i.e., the latent profiles and latent trajectory factors), we solely considered the Time 1 measures of these predictors.

Outcomes measured at the last time point (Time 4: positive and negative affect, performance) were included to the model. Mean differences across profiles were tested using the multivariate delta method (Raykov \& Marcoulides, 2004) implemented via the MODEL CONSTRAINT function.

Supplementary Analyses. Supplementary analyses were conducted to contrast the estimated profiles on the basis of predictors and outcomes assessed at each specific time point (1 to 4). For these analyses, it did not prove possible to incorporate these time-varying covariates directly in the model without changing the nature of the profiles (e.g., Diallo et al., 2017; Marsh et al., 2009). For this reason, we had to rely on a model-based approach proposed by Lanza, Tan, and Bray (2013) and implemented through the Auxiliary (DCON) function (Asparouhov \& Muthén, 2014). The same approach was also used to contrast the profiles with one another based on the time specific factor scores obtained on each specific motivation factors in the preliminary B-ESEM measurement models. These factor scores reflect the specific quality of employees' motivation left unexplained by their global self-determination levels (Howard et al., 2018). The results from this last set of more exploratory analyses are reported at the end of the online supplements (Appendix 4).

\section{Unconditional Models}

\section{Results}

The procedures followed in order to select the optimal GMA solution is fully disclosed in Appendix 3 of the online supplements. This procedure led us to retain the 3-profile solution, thus supporting Hypothesis 1. This solution is graphically presented in Figure 1, and exact parameter estimates are reported in Table S6 of the online supplements. Classification accuracy statistics are reported in Table $\mathrm{S} 7$ of the online supplements, and reveal a very high level of accuracy ranging from .857 to .878 across profiles.

In the interpretation of the profiles, it is important to keep in mind that the trajectories were estimated on the basis of time-invariant factor scores with a mean of 0 and a standard deviation of 1 obtained at the first time point in preliminary analyses reported in the online supplements. This means that a value of 0 corresponds to the average level of global self-determination at Time 1, and that deviations from 
this global mean are directly expressed in $S D$ units. This final solution depicts three profiles characterized by generally stable longitudinal trajectories of global self-determination over time associated with very slight linear or curvilinear tendencies. This stability is generally consistent with the Matching scenarios expected from Hypothesis 3, but fails to support Hypothesis 2. Profile 1 characterized $47.6 \%$ of the participants presenting initial global levels of self-determination corresponding to the sample average, a very slight decreasing tendency over time (corresponding to $.035 S D$ units per month), and a negligible curvilinear tendency (corresponding to .001 SD units per month). This Moderate profile was also associated with the lowest time-specific residuals across time points (corresponding to average deviation from the estimated trajectory ranging from .084 SD units at Time 3 to $.205 S D$ units at Time 1$)$.

Profile 2 characterized $29.7 \%$ of the participants presenting high initial levels of global selfdetermination (.558 SD units higher than the mean) and a slight increasing tendency (.087 SD units per month) coupled with a small negative curvilinear tendency (-.010 SD units per month). This High profile thus followed a slight inverted U-shape trajectory reaching its highest level by the third measurement point and decreasing thereafter. Profile 3 characterized $22.7 \%$ of the participants presenting low initial levels of global self-determination (.604 SD units lower than the sample mean) and a slight decreasing tendency (-.135 SD units per month) coupled with a small positive curvilinear tendency (.011 SD units per month). This Low profile thus followed a slight U-shape trajectory reaching its lowest level by the third measurement point and increasing thereafter. It is noteworthy that the High and Low profiles present similar levels of time-specific residuals. These residuals are two to three times as large as those estimated in the Moderate profile (ranging from .327 to $.575 S D$ units).

\section{Controls}

Once the optimal number of profiles has been selected, we conducted a series of tests aiming to determine whether demographic controls (sex, age, and education level) needed to be retained for subsequent analyses. Results from models incorporating controls are reported at the end of Appendix 3 of the online supplements and support the null effects model. Examination of the detailed parameters estimates from these models supports this conclusion regarding the lack of meaningful associations between the controls and the profiles. Controls were thus excluded from further analyses.

\section{Predictors}

The results from the models incorporating the predictors to the final 3-profile model are reported at the end of Appendix 3 of the online supplements. These results support a model in which the predictors have an effect on the likelihood of profile membership, as well as a class-invariant effect on the initial levels of global self-determination. The results from these predictive analyses are reported in Table 2. These results supported Hypothesis 4 by showing that mental load increased participants' likelihood of membership into Profile 2 (High) relative to Profiles 1 (Moderate) and 3 (Low). Similarly, peer support also increased the likelihood of membership into Profile 2 (High) relative to 1 (Moderate), thus supporting Hypothesis 5. In contrast, emotional load increased the likelihood of membership into Profiles 1 (Moderate) and 2 (High) relative to 3 (Low). Over and above these effects on profile membership, mental load was associated with increases in the initial levels of global self-determination. In contrast, work load was associated with decreases in these initial levels. These results partially supported Hypothesis 6.

Supplementary Analyses. As noted above, supplementary analyses were conducted to consider time-varying associations between the profiles and predictor levels measured at each separate time point. These supplementary results are reported in Table S8 of the online supplements. In contrast with the main results reported above in which predictors were used to statistically predict profile membership through multivariate analyses (in which the effects of each predictor was estimated net of what it shared with the other predictors) also considering their effects on the intercept factor, these supplementary analyses simply assess time-specific associations between predictors and profiles in a univariate manner. These additional results are consistent with the results reported above and show that the highest levels of work load, mental load, emotional load, and peer support were associated, at each time point, with the High profile, followed by the Moderate profile, and then by the Low profile.

\section{Outcomes}

The results from the analyses in which associations between the distal outcome measures and the likelihood of profile membership are reported in Table 3. These results supported Hypothesis 7 by showing that, from an outcomes' perspective, the most desirable profile was the High profile. This 
profile presented the highest levels of performance and positive affect at the end of the study, as well as the lowest levels of negative affect. Although statistically-significant differences mainly emerged between the High and Moderate profiles, the Low profile also presented higher levels of negative affect than the High profile.

Supplementary Analyses. The results from the supplementary analyses in which the univariate timespecific associations between the profiles and the outcomes measured at each separate time point (positive and negative affect only, performance levels were only assessed at the end of the study) are reported in Table S9 of the online supplements. These results show no differences across profiles in terms of positive affect. In contrast, levels of negative affect were higher in the High profile relative to the Low profile at Time 2, and in the Moderate profile relative to the High profile at Time 4. The apparent discrepancies in results obtained as part of these supplementary analyses relative to the main analyses reported here can be explained by a variety of methodological factors, such as: (a) the multivariate nature of the main analyses relative to the univariate nature of the auxiliary analyses; (b) the fact that auxiliary analyses rely on a listwise deletion of participants with missing data on the outcome variables; and (c) the superiority of the direct inclusion approach (Morin \& Litalien, 2018).

\section{Discussion}

The benefits of more self-determined forms of motivation for a variety of educational and workrelated outcomes has been well-established in prior research (Deci et al., 2017; Guay et al., 2008). However, with few exceptions (Nishimura \& Sakurai, 2017), prior research has largely ignored the dynamic nature and longitudinal heterogeneity of individual motivation trajectories. The present study was designed to address this limitation via the identification of the self-determined motivation trajectories of upcoming police officers over the course of their vocational training. We also considered the role of vocational training demands (mental load, work load, and emotional load) and resources (peer support) in the prediction of these trajectories. Finally, the relations between these trajectories and training-specific affect and performance at the end of the program were examined.

\section{Self-Determination Trajectories}

In a recent ground-breaking study, Nishimura and Sakurai (2017) identified two distinct longitudinal profiles which best reflected heterogeneity in early adolescents' trajectories of academic motivation. These two profiles were respectively characterized by increasing and decreasing levels of selfdetermined motivation. Unfortunately, these authors relied on an unnecessarily complex model (simultaneously considering four types of behavioral regulation rather than a single global score of selfdetermined motivation) coupled with a restricted parameterization of GMA. This could have impacted their ability to detect a richer, and more diversified, set of profiles. Perhaps more importantly, these authors did not document the criterion-related validity of these profiles. This casts doubts on their theoretical and practical meaningfulness. In the present study, we relied on a more flexible operationalization of GMA to study longitudinal trajectories estimated based on a recently proposed integrative representation of participants' global levels of self-determined motivation (Howard et al., 2018; Litalien et al., 2017).

This approach allowed us to identify that three distinct profiles best represented the longitudinal trajectories of self-determined motivation of upcoming police officers over the course of their vocational training program, thus supporting Hypothesis 1. In support to Hypothesis 3, but failing to support Hypothesis 2, results revealed generally stable longitudinal trajectories. More precisely, about half of the participants presented initially average levels of self-determined motivation showing a very slight decreasing tendency over time (the Moderate profile). Roughly a third of the participants presented initially high levels of self-determined motivation, which tended to slightly increase over time up to the $25^{\text {th }}$ week of training (the High profile). Finally, about one fifth of the participants came to the training with initially low levels of self-determined motivation, which tended to decrease over time up to the $25^{\text {th }}$ week of training (Low profile). For these last two profiles, self-determination levels displayed a more linear trajectory between the $25^{\text {th }}$ week and the end of the training program. These results suggest that motivation changes might be slightly more pronounced at earlier stages of training, and support the idea that global self-determination may fluctuate as a function of contextual factors related to the vocational training context (Bartholomew et al., 2018; Fernet et al., 2012; Vallerand, 1997). However, it is important to keep in mind that the observed fluctuations remained minimal.

These slight changes associated with the first weeks of the training could possibly be explained by the fact that trainees initially discover a new environment to which they have to adapt. In the present 
study, it is interesting to note that trainees presenting initially high levels of self-determined motivation for entering the training program tended to display slightly increasing trajectories. This suggests that the training context tended to match their positive expectations. In contrast, trainees coming to the program with initially low levels of self-determined motivation tended to display slightly decreasing trajectories over time. This suggests a good match between the training context and their lower expectations. Once the training context becomes more familiar however, these trajectories would become more stable.

This further stabilization occurring within already stable trajectories is well-aligned with the idea that these trajectories reflect the three Matching scenarios (High, Moderate, and Low) from the occupational socialization literature identified by Solinger et al. (2013) as best reflecting the onboarding trajectories of affective commitment characterizing a majority of organizational newcomers. Despite this similarity in results, the occupational socialization literature also suggests the presence of two less frequent additional scenarios that could not be identified in the present study (Boswell et al., 2005; Solinger et al., 2013; Weiss, 1978). These Learning to Love and Honeymoon-Hangover scenarios are proposed to reflect the presence of a mismatch between participants' expectancies and their new work or training contexts. This mismatch could be positive, when the context exceeds expectations (Learning to Love), or negative, when the context is a source of disappointment (Honeymoon-Hangover). At least two different interpretations could be used to explain this apparent discrepancy. First, these socialization scenarios were initially proposed to describe the process of entering a new occupation. It is thus possible that the more time-restricted nature of vocational training lends itself to fewer changes over time. For instance, the most disappointed or exuberant trainees could decide to bid their time to see how the true work context would differ from the training context. Future research in which trainees are followed over time into their new occupation would be need to test this interpretation. Still, a second interpretation remains possible whereby the current results could be function of the specific professional (police) and cultural (France) context considered here. In France, most people entering vocational training to enter the police force come from a very similar professional background in the military or security sector. They may thus be already familiar with the specific context that characterizes police work and training, leading to an overestimation of the stability of these longitudinal trajectories. However, information on trainees' background was not available in this study. Future research is thus needed to confirm that this background could predict profile membership. More generally, future research covering a broader range of vocational training programs would be needed to test this second interpretation.

A final noteworthy aspect of these results is the observation that higher levels of state-like deviations (as reflected in the time-specific residuals representing deviations from the model estimated polynomial trajectories) tended to be associated with the more extreme (High/Low) trajectories of self-determined motivation, rather than with the Moderate trajectory. These results are particularly interesting in that they stand in sharp contrast with those obtained in the study of self-concept trajectories. Indeed, they revealed that higher self-concept levels tended to be more stable over time whereas lower self-concept levels tended to fluctuate widely over time (i.e., the self-equilibrium hypothesis; Morin, Maïano et al., 2013, 2017; Mund \& Neyer, 2016). As discussed by Morin, Maïano et al. (2013, 2017), such patterns of associations between levels and stability in trajectories analyses can only be revealed by GMA. Clearly, additional research is needed to better understand how two constructs so intimately related (e.g., Leary \& Tangney, 2012; Ryan \& Deci, 2017; Wigfield \& Eccles, 2000) could be associated with such discrepant longitudinal mechanisms at the higher end of the spectrum. Before that however, additional research would be needed to assess the extent to which the current results would generalize to other populations and developmental periods.

\section{Predictors of the Self-Determination Trajectories}

Our results showed that the trajectory profiles were independent from individuals' demographic characteristics (sex, age, and education level). More importantly, our results also supported the role of resources and demands associated with the training context in the prediction of these trajectories. In support of Hypothesis 5, we found that perceptions of having access to higher levels of peer support were associated with an increased likelihood of membership into the High profile relative to the Moderate one. Likewise, in support of Hypothesis 6, we found that work load perceptions were associated with decreases in participants' initial levels of self-determined motivation. These results are in line with prior variable-centered studies (e.g., Bartholomew et al., 2018; Fernet et al. 2015; Trépanier et al., 2015) showing that participants' levels of self-determined motivation tend to be negatively associated with the demands and positively associated with the resources present within their 
occupational or educational contexts. These findings are also consistent with previous research demonstrating job demands and resources to be significantly linked to psychological need satisfaction (e.g., De Cooman, Stynen, Van den Broeck, Sels, \& De Witte, 2013; Van den Broeck, Vansteenkiste, De Witte, \& Lens, 2008). These relations may be explained by the fact that demands require considerable energy and thus distract trainees from the satisfaction of their psychological needs. In contrast, job resources may establish conditions of growth and goal achievement, and thereby facilitate psychological need satisfaction. More generally, these results concur with the premises of the job demands-resources model in that perceptions of demands and resources are associated with negative and positive outcomes, respectively (Bakker \& Demerouti, 2007).

In alignment with Hypothesis 4 and with the challenge-hindrance stressor framework (Crawford et al., 2010), we found higher perceptions of mental load to be associated with an increased likelihood of membership into the High profile relative to the Moderate and Low ones. These perceptions were also associated with higher initial levels of self-determined motivation. The fact that opposite results were found to be associated with a hindrance type of demand (work load) and with a challenge type of demand (mental load) underscores the importance of distinguishing demands according to whether there are seen as challenges or hindrances. Despite their stressful nature, challenges can also represent powerful motivating forces for employees. In contrast, hindrances more typically serve to decrease motivation through increasing feelings of helplessness and insecurity (e.g., Widmer, Semmer, Kälin, Jacobshagen, \& Meier, 2012). Challenges tend to foster global self-determination because they enhance individuals' sense that their work is fun, interesting, and meaningful. For instance, Vujčić et al. (2017) showed that workers exposed to job demands of the challenge type tended to experience higher levels of autonomous motivation, positive affect, and work engagement.

Contrary to our expectations formulated in Hypothesis 6, our results showed that emotional load perceptions increased the likelihood of membership into the Moderate and High profiles relative to the Low one. This result thus suggests that emotional load mainly acted as a challenge demand for these trainees. Although we assumed that emotional load should act as a hindrance demand, it is equally possible that the exact impact of emotional load might depend on the valance of the emotions experienced as part of this load. Indeed, regulating negative emotions is more effortful and taxing than regulating positive emotions (Hülsheger \& Schewe, 2011). However, our measure of emotional load did not allow us to assess the valence of these emotions, rather focusing on "emotions" in a general sense. It would be interesting for future research to assess the valence of the emotions experienced as part of this load to more explicitly assess this possibility.

Outside of the challenge-hindrance distinction, it is also important to keep in mind that additional studies have demonstrated positive associations between some forms of job demands and workaholism (e.g., Gillet, Morin, Cougot, \& Gagné, 2017; Molino, Bakker, \& Ghislieri, 2016; Schaufeli, Bakker, van der Heijden, \& Prins, 2009). This observation suggests that at least some of the motivational benefits of job demands, even those of a challenge type, might come at a cost in terms of workaholism. Indeed, the more important the demands, the more trainees may be tempted to invest efforts and energy to meet these demands. This may lead them to experience higher levels of self-determined motivation, work engagement, and workaholism (e.g., Schaufeli, Taris, \& van Rhenen, 2008). Clearly, our ability to explain the apparent benefits of mental and emotional load perceptions for trainees' self-determined motivation remains tentative. Future studies designed to assess the relative effects of additional challenge (e.g., job responsibility, job complexity) and hindrance (e.g., role ambiguity, role conflict) demands, as well as the likely mechanisms involved in these effects (e.g., emotional valence, workaholism) are needed. Future research would also benefit from a consideration of the impact of additional contextual (e.g., organizational support, leadership behaviors, social cohesion; Gillet, Gagné et al., 2013) or personal (e.g., need satisfaction, self-concept, engagement; Howard et al., 2018) characteristics on participants' self-determination trajectories.

\section{Outcomes of the Self-Determination Trajectories}

Our findings clearly support the practical importance of self-determined motivation trajectories in the prediction of outcomes ${ }^{1}$. In accordance with Hypothesis 7, our results revealed well-differentiated

\footnotetext{
${ }^{1}$ Following procedures outlined in Morin et al. (2012), we contrasted the percentage of explained variance in outcome levels taken from a simple variable-centered latent curve model (allowing the intercept and slope factors to predict the outcomes) with that of a model in which the probability of profile membership were also allowed to
} 
associations between profile membership and the outcomes considered in this study. Thus, the High profile was associated with higher levels of positive affect and performance. This profile was also associated with lower levels of negative affect, relative to the Moderate profile. Likewise, the Low profile was associated with higher levels of negative affect than the High profile. These results support SDT's propositions (Deci \& Ryan, 2000) and those from previous research (Gagné \& Deci, 2005; Guay et al., 2008) in demonstrating the positive effects of participants' global levels of self-determined motivation. These results also contributed to establishing the meaningfulness (i.e., criterion-related validity) of the trajectory profiles identified in the present study.

Despite these encouraging results, it is also important to keep in mind that the Moderate and Low profiles did not differ from one another on any of the outcomes considered here. Thus, future studies would be needed to verify the possibility that the benefits of self-determined motivation might be circumscribed to high levels, with only a limited impact being associated with presenting average, versus, low levels of self-determination. Alternatively, the restricted time lag considered in the present study might have made it harder to detect effects emerging over a longer time frame. This time range limited us to the detection of more immediate benefits associated with high levels of self-determination. Importantly, our results are also aligned with those from previous research (Gillet, Becker et al., 2017) in demonstrating that the pattern of associations found between the self-determination trajectories and the outcomes differed as a function of the type of outcomes that was considered. Still, in order to confirm the differential effects of self-determined motivation trajectories on a wider range of outcomes, additional research focusing on markers of cognitive engagement, such as critical thinking, would be particularly informative. Indeed, mounting research evidence supports the role of engagement in training activities as a key determinant of occupational commitment and success that is easier to target for intervention purposes than achievement itself (e.g., Mills \& Fullagar, 2017). Similarly, cognitive style (as a key predictor of performance; e.g., Russell, 1997), as well as dropout intentions or objective dropout data (e.g., Frey, Balzer, \& Ruppert, 2014; Grønborg, 2015) would also be worth considering.

\section{Limitations and Directions for Future Research}

The present study has some limitations. First, we relied on self-report measures, with the exception of observed achievement. Such measures can be impacted by social desirability and self-report biases. We thus encourage researchers to conduct additional research using objective dropout data as well as informant-reported measures of trainees' attitudes and behaviors as ultimate outcomes. Likewise, it would be highly interesting for future research to consider work-related outcomes assessed after the end of the vocational training period once the trainees have started their new occupational roles. Second, it would be informative to look more carefully at the possible impact of the learning context and pedagogical approach used within the context of a greater diversity of vocational training programs, as well as across cultures. This would permit the identification of modifiable levers of improvement for trainees' global levels of self-determination. Third, the motivation trajectories reported here were observed in upcoming police officers over the course of their vocational training. Future research should examine whether the same trajectories emerge in samples from different settings, countries, cultural backgrounds, and developmental periods.

Fourth, the current results are intimately related to the time lag that was considered in this study (Cole \& Maxwell, 2003): A 9-month vocational training program. Although slight changes were observed over time, the bulk of evidence from the present study was that global levels of selfdetermination were quite stable over this time interval. This observation supports the idea that studying changes in motivation requires relatively long time lags and/or major changes in professional lives. Still, it was noteworthy that changes appeared to be slightly more pronounced at the early, rather than late, stages of vocational training. This reinforces the idea that life transitions provide a unique window of opportunity to study developmental changes. In particular, it is possible that relying on a shorter time frame (e.g., daily or weekly diary study: Solinger et al., 2013), especially at the early stages of vocational training, could have allowed us to detect finer-grained fluctuations and associations occurring at the state level. In contrast, relying on a much longer time frame (covering multiple years) could have made it easier to observe associations and changes occurring at a more fundamental trait level. Alternatively,

predict outcome levels. This second model resulted in almost twice as much explanatory power $\left(\mathrm{R}^{2}\right.$ increased from an average of $8.7 \%$ in the latent curve model to $14 \%$ when probabilities of profile membership were taken into account). 
both of these alternative time frames might have hidden the currently observed relations. Ultimately, longitudinal evidence remains stronger than cross-sectional research to clarify the directionality of associations. Yet, such evidence needs to be built incrementally from an accumulation of studies focusing on alternative time frames (Gillet, Morin et al., 2018).

\section{Practical Implications}

This study is the first to document longitudinal trajectories of participants' global levels of selfdetermined motivation in a vocational training context, and to assess the determinants and outcomes of these trajectories. Vocational training is known to represent an important life transition accompanied by major changes in individuals' educational, work, and social environments. Indeed, trainees are exposed to new, unfamiliar, and challenging learning situations, and changing social networks (Masdonati, 2010; Skrobanek, Reissig, \& Müller, 2011). These changes might greatly impact their feelings of being able to act in a purely self-determined manner, with lasting consequences for their upcoming careers. As such, the present results could have a series of important practical implications.

From a practical perspective, our findings suggest that organizations and trainers should seek to increase individuals' global self-determination. Indeed, the High profile was found to be associated with the most positive outcomes. They also revealed that challenging types of demands, as well as resources related to social support, associated with the training context tend to foster more desirable global selfdetermined motivation trajectories. A first implication is thus that organizations and trainers could promote trainees' self-determined motivation by making sure that the training context remains a challenging one. They should also try to avoid adding demands seen as hindering progression. Ensuring that trainees feel supported when facing demands might help them to see them as challenges to be overcome rather than as insurmountable obstacles. Moreover, trainer-focused interventions and support systems should be available to help trainers increase trainees' global levels of self-determination (Hardré \& Reeve, 2009). In the existing literature, numerous studies have shown that autonomy-supportive behaviors were positively related to autonomous motivation (e.g., Gillet, Gagné et al., 2013). Thus, having trainers displaying higher levels of autonomy-supportive behaviors could be associated with a greater likelihood of membership into the most desirable profile (High). The present results also suggest that it might be useful for practitioners to promote peer support systems in order to increase trainees' global levels of self-determined motivation. In order to foster a climate of support among peers, trainers and organizations may implement informal mentoring activities. They may also help to organize informal social events aiming to encourage the development of stronger social ties (Newman, Thanacoody, \& Hui, 2012). Interestingly, Jungert, Van den Broeck, Schreurs, and Osterman (2018) demonstrated the efficacy of a brief intervention (focusing on perspective taking, communication, and collaboration) aiming to train team members to better support the psychological needs for autonomy, competence, and relatedness of their colleagues as a way to improve self-determined motivation levels. Finally and more generally, trainers might promote a supportive culture by providing trainees the resources or materials they need to perform their tasks effectively, by reducing work overload, and by promoting justice and fairness in the way policies are implemented and rewards distributed (Eisenberger \& Stinglhamber, 2011).

Alarcon, G.M. (2011). A meta-analysis of burnout with job demands, resources, and attitudes. Journal of Vocational Behavior, 79, 549-562.

Asparouhov, T., \& Muthén, B.O. (2014). Auxiliary variables in mixture modeling: Three-step approaches using Mplus. Structural Equation Modeling, 21, 1-13.

Asparouhov, T., Muthén, B., \& Morin, A.J.S. (2015). Bayesian structural equation modeling with crossloadings and residual covariances. Journal of Management, 41, 1561-1577.

Bakker, A.B., \& Demerouti, E. (2007). The job demands-resources model: State of the art. Journal of Managerial Psychology, 22, 309-328.

Bartholomew, K.J., Ntoumanis, N., Mouratidis, A., Katartzi, E., Thøgersen-Ntoumani, C., \& Vlachopoulos, S. (2018). Beware of your teaching style: A school-year long investigation of controlling teaching and student motivational experiences. Learning and Instruction, 53, 50-63.

Bauer, K.N., Orvis, K.A., Ely, K., \& Surface, E.A. (2015). Re-examination of motivation in learning contexts: Meta-analytically investigating the role type of motivation plays in the prediction of key training outcomes. Journal of Business and Psychology, 31, 33-50.

Beier, M.E., \& Kanfer, R. (2009). Motivation in training and development: A phase perspective. In 
S.W.J. Kozlowski \& E. Salas (Eds.), Learning, training, and development in organizations (pp. 6597). New York: Psychology Press.

Birch, P., \& Herrington, V. (2011) Policing in practice. Melbourne: Palgrave MacMillan.

Bollen, K.A., \& Curran, P.J. (2006). Latent curve models. Hoboken, NJ: Wiley.

Boswell, W.R., Boudreau, J., \& Tichy, J. (2005). The relationship between employee job change and job satisfaction: The honeymoon-hangover effect. Journal of Applied Psychology, 90, 882-892.

Cavanaugh, M.A., Boswell, W.R., Roehling, M.V., \& Boudreau, J. (2000). An empirical examination of self-reported work stress among U.S. managers. Journal of Applied Psychology, 85, 65-74.

Chemolli, E., \& Gagné, M. (2014). Evidence against the continuum structure underlying motivation measures derived from self-determination theory. Psychological Assessment, 26, 575-585.

Cole, D.A., \& Maxwell, S.E. (2003). Testing mediational models with longitudinal data: Questions and tips in the use of structural equation modeling. Journal of Abnormal Psychology, 112, 558-577.

Colquitt, J.A., LePine, J.A., \& Noe, R. (2000). Toward an integrative theory of training motivation: A meta-analytic path analysis of 20 years of research. Journal of Applied Psychology, 85, 679-707.

Crawford, E.R., LePine, J.A., \& Rich, B.L. (2010). Linking job demands and resources to employee engagement and burnout. Journal of Applied Psychology, 95, 834-848.

Curry, D.H., Caplan, P., \& Knuppel, J. (1994). Transfer of training and adult learning (TOTAL). Journal of Continuing Social Work Education, 6, 8-14.

De Cooman, R., Stynen, D., van den Broeck, A., Sels, L., \& De Witte, H. (2013). How job characteristics relate to need satisfaction and autonomous motivation: Implications for work effort. Journal of Applied Social Psychology, 43, 1342-1352.

Deci, E.L., Olafsen, A., \& Ryan, R.M. (2017). Self-determination theory in work organizations: The state of science. Annual Review of Organizational Psychology \& Organizational Behavior, 19-43.

Deci, E.L., \& Ryan, R.M. (2000). The "what" and "why" of goal pursuits: Human needs and the selfdetermination of behavior. Psychological Inquiry, 11, 227-268.

Diallo, T.M.O., Morin, A.J.S., \& Lu, H. (2016). Impact of misspecifications of the latent variancecovariance and residual matrices on the class enumeration accuracy of growth mixture models. Structural Equation Modeling, 23, 507-531.

Diallo, T.M.O., Morin, A.J.S., \& Lu, H. (2017). The impact of total and partial inclusion or exclusion of active and inactive time invariant covariates in growth mixture models. Psychological Methods, $22,166-190$.

Duran, F., Woodhams, J., \& Bishopp, D. (2018). An interview study of the experiences of police officers in regard to psychological contract and wellbeing. Journal of Police and Criminal Psychology. Early view. doi: 10.1007/s11896-018-9275-z

Dysvik, A., \& Kuvaas, B. (2008). The relationship between perceived training opportunities, work motivation and employee motivation. International Journal of Training \& Development, 12, 138-157.

Eisenberger, R., \& Stinglhamber, F. (2011). Perceived organizational support: Fostering enthusiastic and productive employees. Washington, DC: APA Books.

Enders, C.K. (2010). Applied missing data analysis. New York: Guilford.

Evers, A.T., Van der Heijden, B.I.J.M., Kreijns, K., \& Vermeulen, M. (2016). Job demands, resources and flexible competence: The mediating role of teachers' professional development at work. Journal of Career Development, 43, 227-243.

Fernet, C., Austin, S., \& Vallerand, R.J. (2012). The effects of work motivation on employee exhaustion and commitment: An extension of the JD-R model. Work \& Stress, 26, 213-229.

Fernet, C., Chanal, J., \& Guay, F. (2017). What fuels the fire: Job- or task-specific motivation (or both)? On the hierarchical and multidimensional nature of teacher motivation in relation to job burnout. Work \& Stress, 31, 145-163.

Fernet, C., Trépanier, S.-G., Austin, S., Gagné, M., \& Forest, J. (2015). Transformational leadership and optimal functioning at work: On the mediating role of employees' perceived job characteristics and motivation. Work \& Stress, 29, 11-31.

Frey, A., Balzer, L., \& Ruppert, J.-J. (2014). Transferable competences of young people with a high dropout risk in vocational training in Germany. International Journal for Educational and Vocational Guidance, 14, 119-134.

Gagné, M., \& Deci, E.L. (2005). Self-determination theory and work motivation. Journal of Organizational Behavior, 26, 331-362. 
Gagné, M., Forest, J., Vansteenkiste, M., Crevier-Braud, L., Van den Broeck, A., Aspeli, A., ... \& Westbye, C. (2015). The Multidimensional Work Motivation Scale: Validation in seven languages and nine countries. European Journal of Work \& Organizational Psychology, 24, 178-196.

Gillet, N., Becker, C., Lafrenière, M.-A.K.., Huart, I., \& Fouquereau, E. (2017). Organizational support, job resources, soldiers' motivational profiles, work engagement, and affect. Military Psychology, $29,418-433$.

Gillet, N., Fouquereau, E., Lafrenière, M.-A.K., \& Huyghebaert, T. (2016). Examining the roles of work autonomous and controlled motivations on satisfaction and anxiety as a function of role ambiguity. The Journal of Psychology: Interdisciplinary and Applied, 150, 644-665.

Gillet, N., Fouquereau, E., Vallerand, R.J., Abraham, J., \& Colombat, P. (2018). The role of workers' motivational profiles in affective and organizational factors. Journal of Happiness Studies, 19, 11511174.

Gillet, N., Gagné, M., Sauvagère, S., \& Fouquereau, E. (2013). The role of supervisor autonomy support, organizational support, and autonomous and controlled motivation in predicting employees satisfaction and turnover intentions. European Journal of Work \& Organizational Psychology, 22, 450-460.

Gillet, N., Morin, A.J.S., Cougot, B., \& Gagné, M. (2017). Workaholism profiles: Associations with determinants, correlates, and outcomes. Journal of Occupational \& Organizational Psychology, 90, 559-586.

Gillet, N., Morin, A.J.S., Huyghebaert, T., Burger, L., Maillot, A., Poulin, A., \& Tricard, E. (2018). University students' need satisfaction trajectories: A growth mixture analysis. Learning and Instruction. Early view. doi: 10.1016/j.learninstruc.2017.11.003

Gillet, N., Morin, A.J.S., \& Reeve, J. (2017). Stability, change, and implications of students' motivation profiles: A latent transition analysis. Contemporary Educational Psychology, 51, 222-239.

Gillet, N., Vallerand, R.J., Lafrenière, M.A., \& Bureau, J.S. (2013). The mediating role of positive and negative affect in the situational motivation-performance relationship: A test of the selfdetermination and broaden-and-build theories. Motivation and Emotion, 37, 465-479.

Graham, J.W. (2009). Missing data analysis: Making it work in the real world. Annual Review of Psychology, 60, 549-576.

Green, B. (2004). Post-traumatic stress disorder in UK police officers. Current Medical Research and Opinion, 20, 1-5.

Grimm, K.J., Ram, N., \& Estabrook, R. (2016). Growth modeling. New York: Guilford.

Grønborg, L. (2015). “... It's like the immigrants stick together, the stupid ones, and the ones who want to learn something": Dynamics of peer relations, social categories, and dropout in vocational educational training. International Journal of Qualitative Studies in Education, 28, 514-532.

Guay, F., Morin, A.J.S., Litalien, D., Valois, P., \& Vallerand, R.J. (2015). Application of exploratory structural equation modeling to evaluate the academic motivation scale. The Journal of Experimental Education, 83, 51-82.

Guay, F., Ratelle, C.F., \& Chanal, J. (2008). Optimal learning in optimal contexts: The role of selfdetermination in education. Canadian Psychology, 49, 233-240.

Gunnel, K., \& Gaudreau, P. (2015). Testing a bi-factor model to disentangle general and specific factors of motivation in self-determination theory. Personality and Individual Differences, 81, 35-40.

Hardré, P.L., \& Reeve, J. (2009). Training corporate managers to adopt a more autonomy-supportive motivating style toward employees: An intervention study. International Journal of Training and Development, 13, 165-184.

Hipp, J.R., \& Bauer, D.J. (2006). Local solutions in the estimation of growth mixture models. Psychological Methods, 11, 36-53.

Howard, J.L., Gagné, M., \& Bureau, J.S. (2017). Testing a continuum structure of self-determined motivation: A meta-analysis. Psychological Bulletin, 143, 1346-1377.

Howard, J.L., Gagné, M., Morin, A.J.S., \& Forest, J. (2018). Using bifactor exploratory structural equation modeling to test for a continuum structure of motivation. Journal of Management. Early view. doi: 10.1177/0149206316645653

Howard, J.L., Gagné, M., Morin, A.J.S., \& Van den Broeck, A. (2016). Motivation profiles at work. Journal of Vocational Behavior, 95-96, 74-89.

Hu, Q., Schaufeli, W.B., \& Taris, T. (2013). Does equity mediate the effects of job demands and job resources on work outcomes? An extension of the job demands-resources model. Career 
Development International, 18, 357-376.

Hülsheger, U.R., \& Schewe, A.F. (2011). On the costs and benefits of emotional labor: A meta-analysis of three decades of research. Journal of Occupational Health Psychology, 16, 361-389.

Huynh, J.Y., Xanthopoulou, D., Winefield, A.H. (2014). The job demands-resources model in emergency service volunteers: Examining the mediating roles of exhaustion, work engagement and organizational connectedness. Work \& Stress, 28, 305-322.

Jowett, S., Adie, J.W., Bartholomew, K.J., Yang, S.X., Gustafsson, H., \& Lopez-Jiménez, A. (2017). Motivational processes in the coach-athlete relationship: A multi-cultural self-determination approach. Psychology of Sport and Exercise, 32, 143-152.

Jungert, T., Van den Broeck, A., Schreurs, B., \& Osterman, U. (2018). How colleagues can support each other's needs and motivation: An intervention on employee work motivation. Applied Psychology: An International Review, 67, 3-29.

Kacmar, K.M., Andrews, M.C., Van Rooy, D.L., Steilberg, R.C., \& Cerrone, S. (2006). Sure everyone can be replaced...but at what cost? Turnover as a predictor of unit-level performance. Academy of Management Journal, 49, 133-144.

Kinnunen, U., Feldt, T., Siltaloppi, M., \& Sonnentag, S. (2011). Job demands-resources model in the context of recovery: Testing recovery experiences as mediators. European Journal of Work and Organizational Psychology, 20, 805-822.

Koen, J., Klehe, U.-C., \& van Vianen, A.E.M. (2015). Employability and job search after compulsory reemployment courses: The role of choice, usefulness, and motivation. Applied Psychology: An International Review, 64, 674-700.

Kyndt, E., Coertjens, L., van Daal, T., Donche, V., Gijbels, D., \& Van Petegem, P. (2015). The development of students' motivation in the transition from secondary to higher education: A longitudinal study. Learning and Individual Differences, 39, 114-123.

Lanza, S.T., Tan, X., \& Bray, B.C. (2013). Latent class analysis with distal outcomes: A flexible modelbased approach. Structural Equation Modeling, 20, 1-26.

Larsen, R. (2011). Missing data imputation versus full information maximum likelihood with second level dependencies. Structural Equation Modeling, 18, 649-662.

Leary, M.R., \& Tangney, J.P. (2012). Handbook of self and identity ( $2^{\text {nd }}$ ed.). New York: Guilford.

LePine, J.A., Podsakoff, N.P., \& LePine, M.A. (2005). A meta-analytic test of the challenge stressorhindrance stressor framework: An explanation for inconsistent relationships among stressors and performance. Academy of Management Journal, 48, 764-775.

Lequeurre, J., Gillet, N., Ragot, C., \& Fouquereau, E. (2013). Validation of a French questionnaire to measure job demands and resources. International Review of Social Psychology, 26, 93-124.

Leroy, N., \& Bressoux, P., (2016). Does amotivation matter more than motivation in predicting mathematics learning gains? A longitudinal study of sixth-grade students in France. Contemporary Educational Psychology, 44-45, 41-53.

Litalien, D., Guay, F., \& Morin, A.J.S. (2015). Motivation for PhD studies: Scale development and validation. Learning and Individual Differences, 41, 1-13.

Litalien, D., Morin, A.J.S., Gagné, M., Vallerand, R.J., Losier, G.F., \& Ryan. R.M. (2017). Evidence of a continuum structure of academic self-determination: A two-study test using a bifactor-ESEM representation of academic motivation. Contemporary Educational Psychology, 51, 67-82.

Marsh, H.W., \& Hau, K.T. (2007). Applications of latent-variable models in educational psychology: The need for methodological-substantive synergies. Contemporary Educational Psychology, 32, 151-170.

Marsh, H.W., Lüdtke, O., Trautwein, U., \& Morin, A.J.S. (2009). Latent profile analysis of academic self-concept dimensions: Synergy of person- and variable-centered approaches to the internal/external frame of reference model. Structural Equation Modeling, 16, 1-35.

Masdonati, J. (2010). The transition from school to vocational education and training: A theoretical model and transition support program. Journal of Employment Counseling, 47, 20-29.

Maulana, R., Opdenakker, M.-C., \& Bosker, R. (2013). Teacher-student interpersonal relationships do change and affect academic motivation: A multilevel growth curve modelling. British Journal of Educational Psychology, 84, 459-482.

Meyer, J.P., Becker, T.E., \& Vandenberghe, C. (2004). Employee commitment and motivation: A conceptual analysis and integrative model. Journal of Applied Psychology, 89, 991-1007.

Meyer, J.P., \& Morin, A.J.S. (2016). A person-centered approach to commitment research: Theory, 
research, and methodology. Journal of Organizational Behavior, 37, 584-612.

Mills, M.J., \& Fullagar, C.J. (2017). Engagement within occupational trainees: Individual difference predictors and commitment outcome. Journal of Vocational Behavior, 98, 35-45.

Millsap, R.E. (2011). Statistical approaches to measurement invariance. New York: Taylor \& Francis.

Molino, M., Bakker, A.B., \& Ghislieri, C. (2016). The role of workaholism in the job demandsresources model. Anxiety, Stress \& Coping: An International Journal, 29, 400-414.

Morin, A.J.S. (2016). Person-centered research strategies in commitment research. In J.P. Meyer (Ed.), The handbook of employee commitment (pp. 490-508). Cheltenham, UK: Edward Elgar.

Morin, A.J.S., Arens, A.K., \& Marsh, H.W. (2016) A bifactor exploratory structural equation modeling framework for the identification of distinct sources of construct-relevant psychometric multidimensionality. Structural Equation Modeling, 23, 116-139.

Morin, A.J.S., Boudrias, J.-S., Marsh, H.W., Madore, I., \& Desrumaux, P. (2016). Further reflections on disentengling shape and level effects in person-centered analyses: An illustration exploring the dimensionality of psychological health. Structural Equation Modeling, 23, 438-454.

Morin, A.J.S., Boudrias, J.-S., Marsh, H.W., McInerney, D.M., Dagenais-Desmarais, V., Madore, I., \& Litalien, D. (2017). Complementary variable- and person-centered approaches to the dimensionality of psychometric constructs: Application to psychological wellbeing at work. Journal of Business and Psychology, 32, 395-419.

Morin, A.J.S., \& Litalien, D. (2018). Mixture modelling for lifespan developmental research. In B. Knight, S.D. Neupert, N.D. Anderson, H.-W. Wahl, \& N.A. Pachana (Eds.), Oxford encyclopedia of psychology and aging. Oxford, UK: Oxford University Press.

Morin, A.J.S., Maïano, C., Marsh, H.W., Nagengast, B., \& Janosz, M. (2013). School life and adolescents' self-esteem trajectories. Child Development, 84, 1967-1988.

Morin, A.J.S., Maïano, C., Nagengast, B., Marsh, H.W., Morizot, J., \& Janosz, M. (2011). Growth mixture modeling of adolescents trajectories of anxiety: The impact of untested invariance assumptions on substantive interpretations. Structural Equation Modeling, 18, 613-648.

Morin A.J.S., Maïano, C., Scalas, L.F., Janosz, M., \& Litalien, D. (2017). Adolescents' body image trajectories: A further test of the self-equilibrium hypothesis. Developmental Psychology, 53, 1501-1521.

Morin, A.J.S, Marsh, H.W, \& Nagengast, B. (2013). Exploratory structural equation modeling: An introduction. In G.R. Hancock \& R.O. Mueller (Eds), Structural equation modeling: A second course ( $2^{\text {nd }}$ ed., pp. 395-436). Greenwich, CT: IAP.

Morin, A.J.S., Meyer, J.P., Creusier, J., \& Biétry, F. (2016). Multiple-group analysis of similarity in latent profile solutions. Organizational Research Methods, 19, 231-254.

Morin, A.J.S., Morizot, J., Boudrias, J.-S., \& Madore, I. (2011). A multifoci person-centered perspective on workplace affective commitment: A latent profile/factor mixture analysis. Organizational Research Methods, 14, 58-90.

Morin, A.J.S., Rodriguez, D., Fallu, J.-S., Maïano, C., \& Janosz, M. (2012). Academic achievement and adolescent smoking: A general growth mixture model. Addiction, 107, 819-828.

Mund, M., \& Neyer, F.J. (2016). Rising high or falling deep? Pathways of self-esteem in a representative German sample. European Journal of Personality, 30, 341-357.

Muthén, B.O. (2002). Beyond SEM: General latent variable modeling. Behaviormetrika, 29, 81-117.

Muthén, L.K., \& Muthén, B.O. (2017). Mplus user's guide. Los Angeles, CA: Muthén \& Muthén.

Nahrgang, J.D., Morgeson, F.P., \& Hofmann, D.A. (2011). Safety at work: A meta-analytic investigation of the link between job demands, job resources, burnout, engagement, and safety outcomes. Journal of Applied Psychology, 96, 71-94.

Newman, A., Thanacoody, R., \& Hui, W. (2012). The effects of perceived organizational support, perceived supervisor support and intra-organizational network resources on turnover intentions: A study of Chinese employees in multinational enterprises. Personnel Review, 41, 56-72.

Nilsson, A. (2010). Vocational education and training - an engine for economic growth and a vehicle for social inclusion? International Journal of Training and Development, 14, 251-272.

Nishimura, T., \& Sakurai, S. (2017). Longitudinal changes in academic motivation in Japan. Journal of Applied Developmental Psychology, 48, 42-48.

Olafsen, A.H., \& Halvari, H. (2017). Motivational mechanisms in the relation between job characteristics and employee functioning. The Spanish Journal of Psychology, 20, E38.

Ployhart, R.E., \& Vandenberg, R.J. (2010). Longitudinal research: The theory, design, and analysis of 
change. Journal of Management, 36, 94-120.

Raykov, T., \& Marcoulides, G.A. (2004). Using the delta method for approximate interval estimation of parameter functions in SEM. Structural Equation Modeling, 11, 621-637.

Roberts, Z., Rogers, A., Thomas, C., \& Spitzmueller, C. (2018). Effects of proactive personality and conscientiousness on motivation. International Journal of Training \& Development, 22, 126-143.

Ryan, R.M., \& Deci, E.L. (2017). Self-determination theory: Basic psychological needs in motivation, development, and wellness. New York: Guilford.

Russell, A.J. (1997). The effect of learner variables cognitive style on learning performance in a vocational training environment. Educational Psychology, 17, 195-208.

Schaufeli, W.B., Bakker, A.B., van der Heijden, F.M.M.A., \& Prins, J.T. (2009).Workaholism among medical residents: It is the combination of working excessively and working compulsively that counts. International Journal of Stress Management, 16, 249-272.

Schaufeli, W.B., Taris, T.W., \& van Rhenen, W. (2008). Workaholism, burnout, and work engagement: Three of a kind or three different kinds of employee well-being. Applied Psychology: An International Review, 57, 173-203.

Skrobanek, J., Reissig, B., \& Müller, M. (2011). Successful placement or displacement in the transition from school to vocational training: The case of lower secondary school pupils. Journal of Youth Studies 14, 811-836.

Skrondal, A., \& Laake, P. (2001). Regression among factor scores. Psychometrika, 66, 563-576.

Solinger, O.N., Van Olffen, W., Roe, R.A., \& Hofmans, J. (2013). On becoming (un) committed: A taxonomy and test of newcomer onboarding scenarios. Organization Science, 24, 1640-1661.

Training Magazine (2017). 2017 Training Industry Report. https://trainingmag.com/trgmagarticle/2017-training-industry-report/

Trépanier, S.-G., Forest, J., Fernet, C., \& Austin, S. (2015). On the psychological and motivational processes linking job characteristics to employee functioning: Insights from self-determination theory. Work \& Stress, 29, 286-305.

Valero, D., Hirschi, A., \& Strauss, K. (2015). Hope in adolescent careers: Mediating effects of work motivation on career outcomes in Swiss apprentices. Journal of Career Development, 42, 381-395.

Vallerand, R.J. (1997). Toward a hierarchical model of intrinsic and extrinsic motivation. In M. Zanna (Ed.), Advances in experimental social psychology (pp. 271-360). New York: Academic Press.

Van den Broeck, A., De Cuyper, N., De Witte, H., \& Vansteenkiste, M. (2010). Not all job demands are equal: Differentiating job hindrances and job challenges in the job demands resources model. European Journal of Work Psychology, 19, 735-759.

Van den Broeck, A., Vansteenkiste, M., De Witte, H., \& Lens, W. (2008). Explaining the relationships between job characteristics, burnout and engagement: The role of basic psychological need satisfaction. Work \& Stress, 22, 277-294.

Van Katwyk, P.T., Fox, S., Spector, P.E., \& Kelloway, E.K. (2000). Using the Job-Related Affective Well-Being Scale (JAWS) to investigate affective responses to work stressors. Journal of Occupational Health Psychology, 5, 219-230.

Van Maanen, J., \& Schein, E.H. (1979). Toward a theory of organizational socialization. Research in Organizational Behavior, 1, 209-264.

Vujčić, M.T., Oerlemans, W.G.M., \& Bakker, A.B. (2017). How challenging was your work today? European Journal of Work and Organizational Psychology, 26, 81-93.

Widmer, P.S., Semmer, N.K., Kälin, W., Jacobshagen, N., \& Meier L.L. (2012). The ambivalence of challenge stressors: Time pressure associated with both negative and positive well-being. Journal of Vocational Behavior, 80, 422-433.

Wigfield, A., \& Eccles, J. S. (2000). Expectancy-value theory of motivation. Contemporary Educational Psychology, 25, 68-81.

Weiss, H.M. (1978). Social learning of work values in organizations. Journal of Applied Psychology, $63,711-718$.

Xanthopoulou, D., Bakker, A., Demerouti, E., \& Schaufeli, W. (2007). The role of personal resources in the job demands-resources model. International Journal of Stress Management, 14, 121-141. 


\section{Table 1}

Correlations between Variables

1. Global Self-Determination (T1)

2. Global Self-Determination (T2) $.807 *$

3. Global Self-Determination (T3) $.805^{*}$

4. Global Self-Determination (T4) .757*

5. Mental Load (T1)

6. Work Load (T1)

7. Emotional Load (T1)

8. Peer Support (T1)

9. Positive Affect (T4)

10. Negative Affect (T4)

11. Performance (T4)

12. Age

\section{$.837^{*}$}

$.381 *$

$.212^{*}$

$.152 *$

$.148^{*}$

$.264^{*}$

.028

$-.039-.047$

$.057 \quad .037$

$-.072 *-.045$

13. Sex

$\begin{array}{lll}.010 & .012 & .003\end{array}$

$\begin{array}{lll}-.022 & -.021 & .007\end{array}$

4.5 .

6.

7. 8.

8.9.

10.

11.

$12 . \quad 13$.

14. Education level

$\begin{array}{llllllllllll}.847^{*} & & & & & & & & & & \\ .410^{*} & .379^{*} & & & & & & & & \\ .220^{*} & .216^{*} & .649^{*} & & & & & & & \\ .151^{*} & .152^{*} & .384^{*} & .829 * & & & & & & \\ .295^{*} & .270^{*} & .543^{*} & .084^{*} & -.126^{*} & & & & & \\ .001 & .012 & .002 & .036 & .035 & .020 & & & & & \\ -.023 & -.033 & -.026 & -.038 & -.024 & -.023 & -.572^{*} & & & & \\ .012 & .040 & .008 & .005 & .003 & -.020 & .123^{*} & -.098^{*} & & & \\ -.029 & -.032 & -.018 & -.040 & -.020 & -.027 & .051 & -.044 & .047 & & \\ .003 & .002 & .029 & .018 & .043 & -.069^{*} & .006 & -.017 & -.010 & .007 & \\ .007 & .009 & -.031 & -.121^{*} & -.098^{*} & .102^{*} & .016 & -.004 & .015 & .040 & -.066^{*}\end{array}$

Note. ${ }^{*} p<.01$; all variables with the exception of performance, age, sex, and education level are estimated from factor scores with a mean of 0 and a standard deviation of 1 . 
Table 2

Results from the Prediction of the Motivation Trajectories

\begin{tabular}{|c|c|c|c|c|c|c|c|c|}
\hline \multirow[b]{2}{*}{ Predictor } & \multicolumn{2}{|l|}{ Intercept } & \multicolumn{2}{|c|}{ Profile 1 Vs Profile 3} & \multicolumn{2}{|c|}{ Profile 2 Vs Profile 3} & \multicolumn{2}{|c|}{ Profile 1 Vs Profile 2} \\
\hline & Coef. (SE) & $\beta$ & Coeff. (SE) & OR & Coeff. $(S E)$ & OR & Coeff. $(S E)$ & OR \\
\hline Mental load & $.282(.061)^{* *}$ & .385 & $.279(.226)$ & 1.322 & $.869(.375)^{*}$ & 2.385 & $-.590(.241)^{*}$ & .554 \\
\hline Work load & $-.143(.067)^{*}$ & -.189 & $-.291(.278)$ & .748 & $-.340(.407)$ & .712 & $.049(.257)$ & 1.050 \\
\hline Emotional load & $.062(.056)$ & .079 & $.691(.240) * *$ & 1.996 & $.745(.342)^{*}$ & 2.106 & $-.055(.214)$ & .946 \\
\hline Peer support & $.067(.040)$ & .095 & $.045(.170)$ & 1.046 & $.299(.243)$ & 1.349 & $-.254(.118)^{*}$ & .776 \\
\hline
\end{tabular}

Note. Coef. = unstandardized regression coefficient; $\beta=$ standardized regression coefficient; OR = odds ratio; predictors are estimated from factor scores with mean of 0 and a standard deviation of $1 ; * p \leq .05 ; * * p \leq .01$.

\section{Table 3}

Outcomes of the Motivation Trajectories

\begin{tabular}{|c|c|c|c|c|}
\hline & Moderate (Profile 1) & High (Profile 2) & Low (Profile 3) & Summary of Statistical \\
\hline Outcome Level & Mean $(\mathrm{CI})$ & Mean $(\mathrm{CI})$ & Mean $(\mathrm{CI})$ & Significance Testing \\
\hline Performance & $-.128[-.263 ; .007]$ & $.124[-.024 ; .272]$ & $.043[-.173 ; .258]$ & $2>1 ; 2=3 ; 1=3$ \\
\hline Positive Affect & $-.080[-.153 ;-.008]$ & $.099[.006 ; .192]$ & $-.087[-.229 ; .054]$ & $2>1 ; 2=3 ; 1=3$ \\
\hline Negative Affect & $.094[.020 ; .169]$ & $-.161[-.267 ;-.054]$ & $.063[-.081 ; .208]$ & $1>2 ; 3>2 ; 1=3$ \\
\hline
\end{tabular}

Note. $\mathrm{CI}=95 \%$ confidence intervals; positive affect and negative affect are estimated from factor scores with mean of 0 and a standard deviation of 1 whereas performance levels were standardized to facilitate interpretations. 


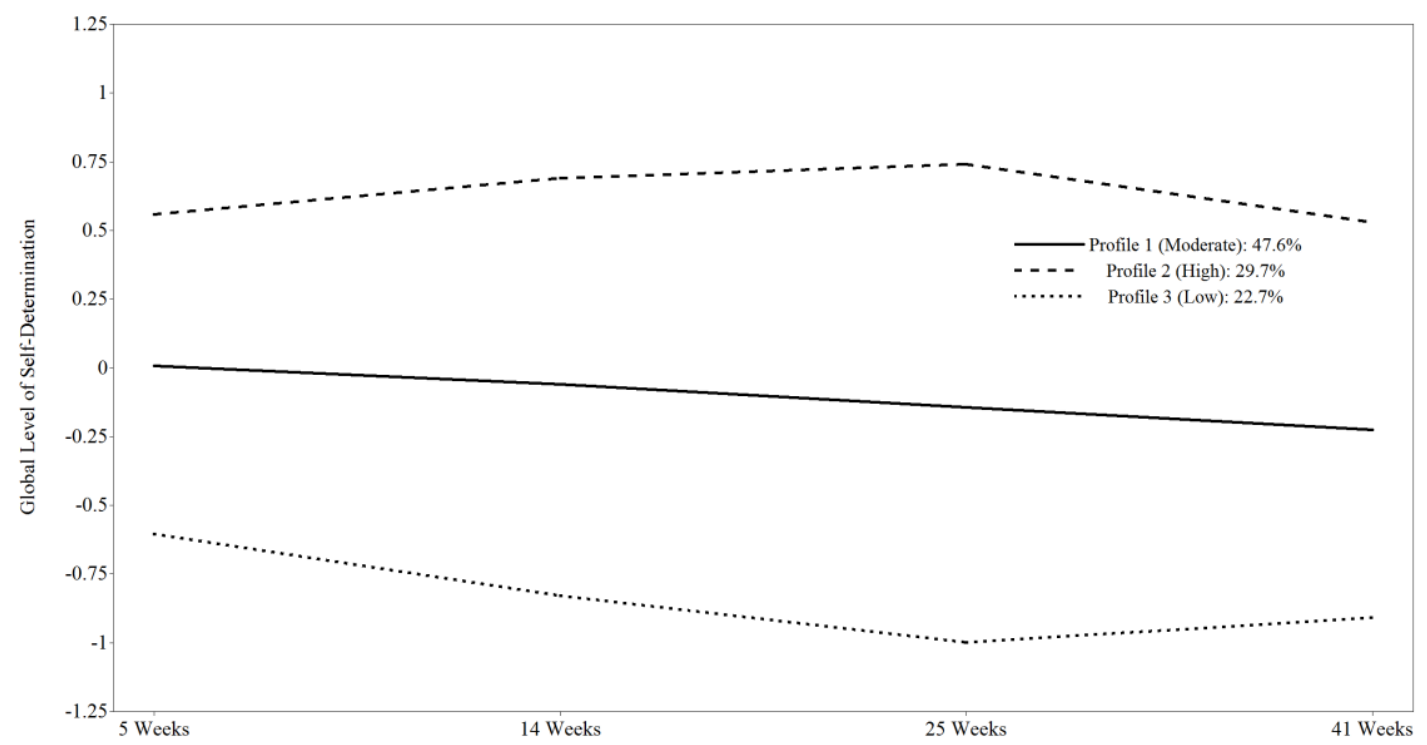

Figure 1. Estimated Growth Trajectories for the Three Self-Determination Profiles.

Note. Trajectories are estimated on the basis of invariant factor scores $(M=0$ and $S D=1$ at Time 1) obtained on the global self-determination factor in analyses reported in the online supplements. 


\section{Online Supplements for: \\ Self-Determination Trajectories during Police Officers' Vocational Training Program: A Growth Mixture}

$\begin{array}{lr}\text { Appendix 1. Preliminary Measurement Models } & \text { S2 }\end{array}$

$\begin{array}{ll}\text { References } & \text { S4 }\end{array}$

Table S1. Goodness-of-Fit Statistics of the Preliminary Longitudinal

Table S2. Standardized Factor Loadings $(\lambda)$ and Uniquenesses $(\delta)$ from $\begin{array}{ll}\text { the Bifactor-ESEM Solutions (Motivation) } & \text { S7 }\end{array}$

Table S3. Fully Invariant Standardized Factor Loadings $(\lambda)$ and Uniquenesses $(\delta)$ from the CFA Solution (Predictors) $\quad$ S9

Table S4. Standardized Factor Loadings $(\lambda)$ and Uniquenesses $(\delta)$ from $\begin{array}{ll}\text { the CFA Solution (Outcomes) } & S 10\end{array}$

Appendix 2. A More Technical Presentation of Growth Mixture Analyses (GMA) S11

Appendix 3. Optimal Model Selection $\quad$ S13

Class Enumeration Process $\quad$ S13

Results: Optimal Number of Profiles $\quad$ S13

$\begin{array}{ll}\text { Results: Optimal Predictive Model } & \text { S13 }\end{array}$

$\begin{array}{ll}\text { References } & \text { S14 }\end{array}$

Figure S1. Elbow Plot of the Information Criteria for the Unconditional
Growth Mixture Analyses

Table S5. Fit Indices from Alternative Unconditional and Conditional
Growth Mixture Analyses

Table S6. Results from the Final Unconditional Three-Class Growth
Mixture Analysis

$\begin{array}{ll}\text { Table S7. Classification Accuracy: Classification Probability for Most Likely } & \\ \text { Profile Membership (Column) as a Function of the Profile Membership (Row) } & \text { S17 }\end{array}$

$\begin{array}{ll}\text { Table S8. Time-Specific Associations between the Predictors and the } & \text { S18 } \\ \text { Self-Determination Trajectories }\end{array}$

Table S9. Time-Specific Associations between the Outcomes and the
Self-Determination Trajectories

Appendix 4. Specific Motivation Factors: Supplementary Analyses $\quad$ S19

Table S10. Time-Specific Associations between the Specific Motivation
Factors and the Self-Determination Trajectories 


\section{Appendix 1. Preliminary Measurement Models}

As for models reported in the main manuscript, these preliminary measurement models were estimated using Mplus 8 (Muthén \& Muthén, 2017), the robust maximum likelihood (MLR) estimator, and Full Information Maximum Likelihood (FIML; Enders, 2010; Graham, 2009) estimation. Due to the complexity of the longitudinal models underlying all constructs assessed in the present study, these analyses were conducted separately for the motivation variables, the predictors, and the outcomes. For the motivation measure, a bifactor exploratory structural equation model (bifactor-ESEM; Morin, Arens, \& Marsh, 2016; Morin, Arens, Tran, \& Caci, 2016; Morin, Boudrias et al., 2016, 2017) including one global factor (G-factor: global quantity of self-determination) and six specific orthogonal factors (Sfactors: intrinsic motivation, identified regulation, introjected regulation, external-social regulation, external-material regulation, and amotivation) was estimated based on Howard, Gagné, Morin, and Forest's (2018; also see Litalien et al., 2017) recommendations. However, following Morin and colleagues (Morin, Arens, \& Marsh, 2016; Morin, Boudrias et al., 2016, 2017), we started by a systematic comparison of the a priori bifactor-ESEM solution with alternative confirmatory factor analytic (CFA), ESEM, and bifactor-CFA solutions at each separate time point to ascertain the superiority of the bifactor-ESEM solution. The results from these comparisons, which supported the bifactor-ESEM are available upon request.

For the predictors, a CFA approach including four correlated first-order factors (mental load, work load, emotional load, and peer support) was estimated. For the outcomes, a CFA approach including two correlated first-order factors (positive and negative affect) was estimated. Longitudinal models were directly estimated across all four time waves and included a total of 28 factors ([1 G-factor $+6 \mathrm{~S}$-factors] $\mathrm{x} 4$ time waves) for the motivation measure, 16 factors for the predictors ( 4 factors $\mathrm{x} 4$ time waves), and 8 factors for the outcomes measures ( 2 factors $\mathrm{x} 4$ time waves). All factors were freely allowed to correlate across time points. A priori correlated uniquenesses between matching indicators of the factors utilized at the different time points were included in the longitudinal models, as well as between two pairs of items presenting parallel wording in the predictor model (e.g., Marsh et al., 2013; Marsh, Scalas, \& Nagengast, 2010). The B-ESEM (motivation) models were estimated using confirmatory orthogonal bifactor target rotation, in which all target loadings of items on their a priori factors were freely estimated, and all cross-loadings targeted to be as close to zero as possible (Morin, Arens, \& Marsh, 2016).

Before saving the factor scores for our main analyses, we verified that the measurement models operated in the same manner across time waves, through sequential tests of measurement invariance (Millsap, 2011): (1) configural invariance, (2) weak invariance (loadings), (3) strong invariance (loadings and intercepts), (4) strict invariance (loadings, intercepts, and uniquenesses), (5) invariance of the latent variance-covariance matrix (loadings, intercepts, uniquenesses, and latent variances and covariances), and (6) latent means invariance (loadings, intercepts, uniquenesses, latent variances and covariances, and latent means). For the predictor model, an additional step (4b) was included to test the invariance of the correlated uniquenesses included between the two pairs of parallel-worded items.

Given the oversensitivity of the chi-square test $\left(\chi^{2}\right)$ to sample size and minor misspecifications (Marsh, Hau, \& Grayson, 2005), we relied on goodness-of-fit indices to describe the fit of the models (Hu \& Bentler, 1999): The comparative fit index (CFI), the Tucker-Lewis index (TLI), as well as the root mean square error of approximation (RMSEA) and its $90 \%$ confidence interval. Values greater than .90 for the CFI and TLI indicate adequate model fit, although values greater than .95 are preferable. Values smaller than .08 or .06 for the RMSEA respectively support acceptable and excellent model fit. Like the chi square, chi square difference tests present a known sensitivity to sample size and minor model misspecifications so that recent studies suggest complementing this information with changes in CFIs and RMSEAs (Chen, 2007; Cheung \& Rensvold, 2002) in the context of tests of measurement invariance. A $\triangle \mathrm{CFI}$ of .010 or less and a $\triangle$ RMSEA of .015 or less between a more restricted model and the previous one supports the invariance hypothesis.

The goodness-of-fit results from all longitudinal models are reported in Table S1. These results support the adequacy of the a priori longitudinal measurement models underlying all constructs, with all models of configural invariance being associated CFI/TLI $\geq .90$ and all RMSEA $\leq .06$. For the motivation measurement model, the results supported its weak and strong measurement invariance as none of the changes in goodness-of-fit indices exceeded the recommended cut-off scores $(\triangle \mathrm{CFI} / \mathrm{TLI} \leq$ $.010 ; \triangle \mathrm{RMSEA} \leq .015)$. However, the model of strict measurement invariance failed to converge (even 
after increasing the number of iterations and decreasing the convergence criterion), suggesting its failure to uphold strict measurement invariance, an hypothesis that was supported by an examination of the parameter estimates associated with the model of strong invariance. The uniquenesses associated with the model of strong invariance were thus examined, and contrasted using the multivariate delta method (Raykov \& Marcoulides, 2004), in order to locate the non-invariant uniquenesses. This examination resulted in the identification of 3 non-invariant item uniquenesses (suggesting slight increases in unreliability over time for three items). Invariance constraints on these uniquenesses were then relaxed, leading to a model of partial strict invariance that was supported by the data. However, the models of invariance of the latent variance-covariances, and latent means, also failed to be supported by the data $(\triangle \mathrm{CFI} / \mathrm{TLI} \geq .010)$. These results revealed a slight increase in within-sample variability of motivation levels over time, and showed that mean levels of global self-determination, intrinsic motivation, and identified regulation tended to slightly decrease over time, while those of introjected regulation, external-social regulation, external-material regulation, and amotivation tended to increase over time. Because the reliance on bifactor-ESEM measurement models makes it impossible to test models of partial invariance at the latent level, we thus retained the model of partial strict invariance to generate the factor scores used in this study. In this model, the scaling of the factors was achieved by fixing the variances and means of the Time 1 factors, respectively, at 1 and 0 . This allowed us to estimate motivation levels in standardized units at Time 1, and as deviations from Time 1 levels in standardized units at the following time points.

Turning our attention to the predictor measurement model, the results supported the weak, strong, strict, correlated uniquenesses, and latent variance-covariance across time points $(\triangle \mathrm{CFI} / \mathrm{TLI} \leq .010$; $\triangle$ RMSEA $\leq .015)$. As above, these results failed to support the latent mean invariance of all factors across time points. However, a detailed examination of the parameter estimates and modification indices associated with these various models suggested a model of partial invariance which was supported by the data. In this model, invariance constraints were relaxed on six latent means, revealing that levels of mental load and peer support tended to decrease over time. Factors scores for the main analyses were saved from this model of partial latent mean invariance, in which the means of the non-invariant factors were constrained to be 0 at Time 1 and expressed as deviation from Time 1 levels at the remaining time points. All factor variances were constrained to be 1 , and all other latent means were constrained to be 0 . Although only strict measurement invariance is required to ensure that measurement of the constructs remains equivalent across time waves for models based on factor scores (e.g., Millsap, 2011), there are advantages to saving factors scores from models of latent variances, covariances, and means invariance. Indeed, saving factor scores from a model of latent variances and the means invariance (i.e., respectively constrained to take a value of 1 and 0 in all time waves) provides scores that can be readily interpreted in standard deviation units.

Finally, the results supported the weak, but not strong, invariance of the outcomes measurement model. Examination of the parameter estimates of the model of weak invariance and modification indices of the model of strong invariance suggested a model of partial invariance (in which invariance constraints were relaxed on two item intercepts), which was supported by the data. Starting from this model of partial strong invariance, the results supported the model of strict invariance, but not the model of latent variance-covariance invariance due to the fact that the variance of the negative affect factor was slightly lower at Time 1 . When equality constraints were relaxed on this factor, the resulting model of partial latent variance-covariance invariance was supported by the data. Starting from this model, the invariance of the latent means also failed to be supported by the data, leading to a final model of partial latent means invariance which was supported by the data. The results from this model showed that levels of negative affect were slightly lower at Time 1 and Time 2, whereas levels of positive affect were slightly higher at Time 1 . Factor scores were saved from this model of partial latent mean invariance, in which the means and variance of the non-invariant factors were constrained to be respectively 0 and 1 at Time 4 and expressed as deviation from Time 4 levels at the remaining time points. All other latent means were fixed to 0 , and all other latent variances were fixed to 1 .

The final parameter and composite reliability ( $\omega$; McDonald, $\left.1970^{2}\right)$ estimates from these

\footnotetext{
${ }^{2}$ Composite reliability coefficients associated with each of the a priori factors are calculated from the model standardized parameters using McDonald (1970) omega ( $\omega)$ coefficient:
} 
measurement models are reported in Tables S2 (motivation), S3 (predictors), and S4 (outcomes), while the correlations between all variables used in the main analyses are reported in Table 1 of the manuscript. The results from the motivation models were fully in line with Howard et al. (2018) and Litalien et al. (2017) in supporting the interpretation of the G-factor as a reliable ( $\omega=.849$ to .870 across time points) estimate of global levels of self-determination, with strong positive loadings from the identified regulation $\left(M_{|\lambda|}=.530\right)$ and introjected regulation $\left(M_{|\lambda|}=.507\right)$ items, moderate positive loadings from the intrinsic motivation items $\left(M_{|\lambda|}=.357\right.$ : consistent with the interpretation of this factor as assessing self-regulation rather than intrinsic motivation or pleasure), weak loadings from the external-social regulation $\left(M_{|\lambda|}=.295\right)$ and external-material regulation $\left(M_{|\lambda|}=.220\right)$ items, and negative loadings from the amotivation items $\left(M_{\lambda}=-.075\right)$. Also in accordance with Howard et al. (2018) and Litalien et al. (2017), the results revealed: (a) strongly defined S-factors related to intrinsic motivation $\left(M_{|\lambda|}=.716 ; \omega\right.$ $=.735$ to 869$)$, external-social regulation $\left(M_{|\lambda|}=.607 ; \omega=.602\right.$ to .714$)$, and amotivation $\left(M_{|\lambda|}=.761\right.$; $\omega=.856$ to .925$)$; (b) moderately defined factors related to introjected regulation $\left(M_{|\lambda|}=.376 ; \omega=.597\right.$ to .623$)$ and external-material regulation $\left(M_{|\lambda|}=.491 ; \omega=.586\right.$ to .621$)$; and (c) a more weakly defined S-Factor related to identified regulation $\left(M_{|\lambda|}=.066 ; \omega=.003\right.$ to .028$)$ due to the fact that the items associated with this factor mainly served to define the G-factor. Still, it is important to note that, in latent variable models such as those, scores on the latent variables themselves can be considered to be perfectly controlled for measurement error. Finally, all predictors and outcomes models resulted in factors that were well-defined through high target factor loadings $\left(\mathrm{M}_{|\mathrm{l}|}=.700\right)$, resulting in fully acceptable modelbased composite reliability coefficients: (a) mental load $\left(M_{|\lambda|}=.813 ; \omega=.886\right)$; (b) work load $\left(M_{|\lambda|}=\right.$ $.704 ; \omega=.798) ;(\mathrm{c})$ emotional load $\left(M_{|\lambda|}=.667 ; \omega=.763\right)$; (d) peer support $\left(M_{|\lambda|}=.878 ; \omega=.932\right)$; (e) positive affect $\left(M_{|\lambda|}=.664 ; \omega=.802\right)$; and (f) negative affect $\left(M_{|\lambda|}=.683 ; \omega=.776\right.$ at Time 1 and .839 at Times 2-3-4).

\section{References used in this supplement}

Chen, F.F. (2007). Sensitivity of goodness of fit indexes to lack of measurement. Structural Equation Modeling, 14, 464-504.

Cheung, G.W., \& Rensvold, R.B. (2002). Evaluating goodness-of fit indexes for testing measurement invariance. Structural Equation Modeling, 9, 233-255.

Enders, C.K. (2010). Applied missing data analysis. New York: Guilford.

Graham, J.W. (2009). Missing data analysis: Making it work in the real world. Annual Review of Psychology, 60, 549-576.

Howard, J.L., Gagné, M., Morin, A.J.S., \& Forest, J. (2018). Using bifactor exploratory structural equation modeling to test for a continuum structure of motivation. Journal of Management. Advance online publication. doi: 10.1177/0149206316645653

Hu, L.-T., \& Bentler, P.M. (1999). Cutoff criteria for fit indexes in covariance structure analysis: Conventional criteria versus new alternatives. Structural Equation Modeling, 6, 1-55.

Litalien, D., Morin, A.J.S., Gagné, M., Vallerand, R.J., Losier, G.F., \& Ryan, R.M. (2017). Evidence of a continuum structure of academic self-determination: A two-study test using a bifactor-ESEM representation of academic motivation. Contemporary Educational Psychology, 51, 67-82.

Marsh, H.W., Abduljabbar, A.S., Abu-Hilal, M., Morin, A.J.S., Abdelfattah, F., Leung, K.C., Xu, M.K., Nagengast, B., \& Parker, P. (2013). Factor structure, discriminant and convergent validity of TIMSS math and science motivation measures: A comparison of USA and Saudi Arabia. Journal of Educational Psychology, 105, 108-128.

Marsh, H.W., Hau, K., \& Grayson, D. (2005). Goodness of fit in structural equation models. In A. Maydeu-Olivares \& J.J. McArdle (Eds.), Contemporary psychometrics: A festschrift for Roderick P. McDonald (pp. 275-340). Mahwah, NJ: Erlbaum.

Marsh, H.W., Scalas, L.F., \& Nagengast, B. (2010). Longitudinal tests of competing factor structures

$$
\omega=\frac{\left(\sum\left|\lambda_{i}\right|\right)^{2}}{\left[\left(\sum\left|\lambda_{i}\right|\right)^{2}+\sum \delta_{i}\right]}
$$

where $\left|\lambda_{i}\right|$ are the standardized factor loadings associated with a factor in absolute values, and $\delta i$, the item uniquenesses. The numerator, where the factor loadings are summed, and then squared, reflects the proportion of the variance in indicators that reflect true score variance, whereas the denominator reflects total amount of variance in the items including both true score variance and random measurement errors (reflects by the sum of the items uniquenesses associated with a factor). 
for the Rosenberg self-esteem scale: Traits, ephemeral artifacts, and stable response styles. Psychological Assessment, 22, 366-381.

McDonald, R.P. (1970). Theoretical foundations of principal factor analysis, canonical factor analysis, and alpha factor analysis. British Journal of Mathematical \& Statistical Psychology, 23, 1-21.

Millsap, R.E. (2011). Statistical approaches to measurement invariance. New York: Taylor \& Francis.

Morin, A.J.S., Arens, A., \& Marsh, H. (2016). A bifactor exploratory structural equation modeling framework for the identification of distinct sources of construct-relevant psychometric multidimensionality. Structural Equation Modeling, 23, 116-139.

Morin, A.J.S., Arens, K., Tran, A., \& Caci, H. (2016). Exploring sources of construct-relevant multidimensionality in psychiatric measurement: A tutorial and illustration using the Composite Scale of Morningness. International Journal of Methods in Psychiatric Research, 25, 277-288.

Morin, A.J.S., Boudrias, J.-S., Marsh, H.W., Madore, I., \& Desrumeaux, P. (2016). Further reflections on disentengling shape and level effects in person-centered analyses: An illustration exploring the dimensionality of psychological health. Structural Equation Modeling, 23, 438-454.

Morin, A.J.S., Boudrias, J.-S., Marsh, H.W., McInerney, D.M., Dagenais-Desmarais, V., Madore, I., \& Litalien, D. (2017). Complementary variable- and person-centered approaches to the dimensionality of psychometric constructs: Application to psychological wellbeing at work. Journal of Business and Psychology, 32, 395-419.

Muthén, L.K., \& Muthén, B.O. (2017). Mplus user's guide. Los Angeles: Muthén \& Muthén.

Raykov, T., \& Marcoulides, G.A. (2004). Using the delta method for approximate interval estimation of parameter functions in SEM. Structural Equation Modeling, 11, 621-637. 
Table S1

Goodness-of-Fit Statistics of the Preliminary Longitudinal Measurement Models

\begin{tabular}{|c|c|c|c|c|c|c|c|c|c|c|}
\hline Description & $\chi^{2}(d f)$ & CFI & TLI & RSEA & $90 \% \mathrm{CI}$ & $\mathrm{CM}$ & $\Delta \chi^{2}(d f)$ & $\Delta \mathrm{CFI}$ & $\Delta \mathrm{TLI}$ & $\Delta \mathrm{RMSE}$ \\
\hline \multicolumn{11}{|l|}{ Motivation } \\
\hline M1. Configural invariance & $3390.183(2051)^{*}$ & .956 & .939 & .020 & {$[.019 ; .021]$} & - & - & - & - & - \\
\hline M2. Weak invariance & $3673.012(2303)^{*}$ & .955 & .944 & .019 & {$[.018 ; .020]$} & M1 & $317.118(252)^{*}$ & -.001 & +.005 & -.001 \\
\hline M3. Strong invariance & $3735.373(2339)^{*}$ & .954 & .944 & .019 & {$[.018 ; .020]$} & M2 & $62.844(36)^{*}$ & -.001 & .000 & .000 \\
\hline M4. Strict invariance & Did not converge & & & & & & & & & \\
\hline M5. Partial strict invariance & $3918.093(2393)^{*}$ & .950 & .940 & .020 & 021] & M3 & $130.646(54)^{*}$ & -.004 & -.004 & +.001 \\
\hline M6. Latent variance-covariance & $4714.143(2477)^{*}$ & .927 & .916 & .023 & {$[.022 ; .024]$} & M5 & 626.140 & -.023 & -.024 & +.003 \\
\hline M7. Latent means invariance & $4508.006(2414)^{*}$ & .931 & .919 & .023 & {$[.022 ; .024]$} & M5 & $596.277(21)^{*}$ & -.019 & -.021 & +.003 \\
\hline \multicolumn{11}{|l|}{ Predictors } \\
\hline M1. Configura & 380 & .925 & .912 & .027 & 28] & - & - & - & - & - \\
\hline M2. I & 3865 & .924 & .913 & .027 & 28] & M1 & 61. & -.001 & -.001 & 0 \\
\hline M3. & 411 & .916 & .906 & .028 & $.029]$ & M2 & $271.344(3$ & -.008 & -.007 & +.001 \\
\hline M4. S & 4253.34 & .913 & .905 & .028 & {$[.027 ; .029]$} & M3 & $125.227(4$ & -.003 & -.001 & .000 \\
\hline M5. & 4259.1 & .913 & .905 & .028 & {$[.027 ; .029]$} & M4 & $11.478(6)$ & .000 & .000 & .000 \\
\hline M6. I & $(1884)^{*}$ & .906 & .900 & .029 & {$[.028 ; .030]$} & M5 & $221.395(30)^{*}$ & -.007 & -.005 & +.001 \\
\hline M7. I & $4854.448(1896)^{*}$ & .893 & .886 & .031 & {$[.030$} & M6 & $433.725(12)^{*}$ & -.013 & -.014 & +.002 \\
\hline M8. Partia & $4604.269(1890)^{*}$ & .902 & .900 & .029 & {$[.030 ; .031]$} & M6 & $120.440(6)^{*}$ & -.004 & .000 & .000 \\
\hline \multicolumn{11}{|l|}{ Outcomes } \\
\hline M1. Config & * $*$ & .933 & .920 & .026 & {$[.025 ; .028]$} & - & - & - & - & - \\
\hline M2. I & $1458.912(676)^{*}$ & .930 & .920 & .027 & {$[.025 ; .028]$} & M1 & $54.197(24)^{*}$ & -.003 & .000 & +.001 \\
\hline M3. Stron & $1703.858(700)^{*}$ & .911 & .901 & .030 & {$[.028 ; .031]$} & M2 & $262.672(24)^{*}$ & -.019 & -.019 & +.003 \\
\hline M4. Partial strong invariance & $1570.082(698)^{*}$ & .923 & .913 & .028 & {$[.026 ; .029]$} & M2 & $119.401(22)^{*}$ & -007 & -.007 & +.001 \\
\hline M5. Strict invariance & $1652.120(728)^{*}$ & .918 & .912 & .028 & {$[.026 ; .030]$} & M4 & $76.607(30)^{*}$ & -.005 & -.001 & .000 \\
\hline M6. Latent variance-cov & $1811.409(737)^{*}$ & .905 & .899 & .030 & {$[.028 ; .031]$} & M5 & $104.830(9)^{*}$ & -.013 & -.013 & +.002 \\
\hline M7. Partial latent var.-covar. invariance & $1734.342(736)^{*}$ & .911 & .906 & .029 & {$[.027 ; .030]$} & M5 & $58.958(8)^{*}$ & -.007 & -.006 & +.001 \\
\hline M8. Latent means invariance & $2031.399(742)^{*}$ & .885 & .880 & .032 & {$[.031 ; .034]$} & M7 & $363.828(6)^{*}$ & -.026 & -.026 & +.003 \\
\hline M9. Partial latent means invariance & $1772.898(739)^{*}$ & .908 & .903 & .029 & {$[.027 ; .031]$} & M7 & $42.045(3)^{*}$ & -.003 & -.003 & .000 \\
\hline
\end{tabular}

Note. $* p<.01 ; \chi^{2}$ : robust chi-square test of exact fit; $d f$ : degrees of freedom; CFI: comparative fit index; TLI: Tucker-Lewis index; RMSEA: root mean square error of approximation; $90 \%$ CI: $90 \%$ confidence interval; CM: comparison model; $\Delta$ : change in fit relative to the CM. 
Table S2

Standardized Factor Loadings $(\lambda)$ and Uniquenesses $(\delta)$ from the Bifactor-ESEM Solutions (Motivation)

\begin{tabular}{|c|c|c|c|c|c|c|c|c|c|c|c|c|c|c|c|c|}
\hline Items & $\begin{array}{c}\text { Time } 1 \\
\mathrm{G} \\
\lambda\end{array}$ & $\begin{array}{c}\text { S-IM } \\
\lambda\end{array}$ & $\begin{array}{c}\text { S-IDR } \\
\lambda\end{array}$ & $\begin{array}{c}\text { S-INR } \\
\lambda\end{array}$ & $\begin{array}{c}\text { S-EXRS } \\
\lambda \\
\end{array}$ & $\begin{array}{c}\text { S-EXRM } \\
\lambda \\
\end{array}$ & $\begin{array}{c}\text { S-AMO } \\
\lambda \\
\end{array}$ & $\delta$ & $\begin{array}{c}\text { Time } 2 \\
\mathrm{G} \\
\lambda\end{array}$ & $\begin{array}{c}\text { S-IM } \\
\lambda\end{array}$ & $\begin{array}{c}\text { S-IDR } \\
\lambda\end{array}$ & $\begin{array}{c}\text { S-INR } \\
\lambda\end{array}$ & $\begin{array}{c}\text { S-EXRS } \\
\lambda \\
\end{array}$ & $\begin{array}{c}\text { S-EXRM } \\
\lambda \\
\end{array}$ & $\begin{array}{c}\text { S-AMO } \\
\lambda\end{array}$ & $\delta$ \\
\hline \multicolumn{17}{|l|}{ IM } \\
\hline Item 1 & .364 & .648 & -.009 & -.119 & -.110 & -.114 & -.077 & .402 & .347 & .671 & -.027 & -.122 & -.124 & -.109 & -.127 & .368 \\
\hline Item 2 & .402 & .691 & .048 & -.074 & -.124 & -.051 & -.059 & .331 & .378 & .705 & .139 & -.074 & -.137 & -.048 & -.096 & .294 \\
\hline Item 3 & .370 & .662 & -.035 & -.085 & -.110 & -.067 & -.161 & .375 & .345 & .669 & -.101 & -.085 & -.120 & -.063 & -.259 & .327 \\
\hline \multicolumn{17}{|l|}{ IDR } \\
\hline Item 1 & .634 & .159 & .002 & -.153 & -.027 & -.093 & -.059 & .537 & .626 & .171 & .005 & -.162 & -.031 & -.093 & -.100 & .528 \\
\hline Item 2 & .472 & .526 & .037 & -.081 & -.226 & -.028 & -.067 & .436 & .449 & .544 & .108 & -.083 & -.253 & -.026 & -.109 & .397 \\
\hline Item 3 & .508 & .240 & -.032 & .075 & -.124 & -.086 & -.051 & .652 & .495 & .254 & -.096 & .078 & -.142 & -.084 & -.286 & .622 \\
\hline \multicolumn{17}{|l|}{ INR } \\
\hline Item 1 & .721 & -.228 & -.032 & -.098 & .205 & -.017 & .005 & .376 & .738 & -.253 & -.101 & -.107 & .247 & -.018 & .009 & .397 \\
\hline Item 2 & .683 & .086 & .063 & -.034 & -.102 & .060 & .024 & .506 & .673 & .092 & .192 & -.036 & -119 & .060 & .040 & .495 \\
\hline Item 3 & .300 & -.105 & -.012 & .721 & .185 & .025 & .063 & .340 & .265 & -.101 & -.033 & .682 & .192 & .022 & .096 & .267 \\
\hline Item 4 & .350 & -.106 & .002 & .684 & .057 & .140 & .057 & .373 & .316 & -.105 & .005 & .663 & .061 & .127 & .089 & .307 \\
\hline \multicolumn{17}{|l|}{ EXRS } \\
\hline Item 1 & .418 & -.118 & -.064 & -.071 & .559 & .054 & .027 & .487 & .396 & -.122 & -.188 & -.072 & .623 & .051 & .043 & .440 \\
\hline Item 2 & .355 & -.084 & .044 & .129 & .633 & .156 & .130 & .406 & .313 & -.080 & .121 & .122 & .657 & .138 & .197 & .318 \\
\hline Item 3 & .194 & -.095 & .041 & .330 & .607 & .162 & .212 & .402 & .158 & -.084 & .104 & .288 & .582 & .133 & .297 & .269 \\
\hline \multicolumn{17}{|l|}{ EXRM } \\
\hline Item 1 & .068 & -.104 & -.033 & .102 & .271 & .571 & .153 & .550 & .060 & -.099 & -.089 & .097 & .281 & .507 & .232 & .429 \\
\hline Item 2 & .246 & -.066 & .014 & .043 & .068 & .794 & -.007 & .297 & .244 & -.071 & .042 & .046 & .080 & .795 & -.012 & .295 \\
\hline Item 3 & .346 & .033 & .012 & .168 & -.043 & .171 & .013 & .820 & .341 & .035 & .035 & .177 & -.049 & .169 & .021 & .799 \\
\hline \multicolumn{17}{|l|}{ AMO } \\
\hline Item 1 & -.098 & -.259 & .074 & .128 & .288 & .094 & .734 & .272 & -.059 & -.170 & .139 & .083 & .205 & .057 & .763 & .286 \\
\hline Item 2 & -.139 & -.205 & .023 & .170 & .309 & .102 & .792 & .176 & -.079 & -.127 & .040 & .103 & .207 & .059 & .776 & .216 \\
\hline Item 3 & -.110 & -.203 & -.132 & .157 & .247 & .132 & .677 & .368 & -.067 & -.133 & -.248 & .102 & .176 & .080 & .705 & .136 \\
\hline$\omega$ & .850 & .783 & .003 & .597 & .714 & .586 & .856 & & .849 & .809 & .027 & .602 & .771 & .587 & .888 & \\
\hline
\end{tabular}

Note. $\mathrm{G}=$ global factor estimated as part of a bifactor model; $\mathrm{S}=$ specific factor estimated as part of a bifactor model; $\lambda$ : factor loading; $\delta$ : item uniqueness; $\omega$ : omega coefficient of model-based composite reliability; IM = intrinsic motivation; IDR = identified regulation; INR = introjected regulation; EXRS = external regulation-social; EXRM = external regulation-material; AMO = amotivation; non-significant parameters $(p \geq .05)$ are marked in italics. 
Table S2 (Continued)

\begin{tabular}{|c|c|c|c|c|c|c|c|c|c|c|c|c|c|c|c|c|}
\hline Items & $\begin{array}{c}\text { Time } 3 \\
\mathrm{G} \\
\lambda\end{array}$ & $\begin{array}{c}\text { S-IM } \\
\lambda\end{array}$ & $\begin{array}{c}\text { S-IDR } \\
\lambda\end{array}$ & $\begin{array}{c}\text { S-INR } \\
\lambda\end{array}$ & $\begin{array}{c}\text { S-EXRS } \\
\Lambda\end{array}$ & $\begin{array}{c}\text { S-EXRM } \\
\lambda\end{array}$ & $\begin{array}{c}\text { S-AMO } \\
\lambda\end{array}$ & $\delta$ & $\begin{array}{c}\text { Time } 4 \\
\mathrm{G} \\
\lambda\end{array}$ & $\begin{array}{c}\text { S-IM } \\
\lambda\end{array}$ & $\begin{array}{c}\text { S-IDR } \\
\lambda\end{array}$ & $\begin{array}{c}\text { S-INR } \\
\lambda\end{array}$ & $\begin{array}{c}\text { S-EXRS } \\
\lambda\end{array}$ & $\begin{array}{c}\text { S-EXRM } \\
\lambda\end{array}$ & $\begin{array}{c}\text { S-AMO } \\
\lambda\end{array}$ & $\delta$ \\
\hline \multicolumn{17}{|l|}{$\mathrm{IM}$} \\
\hline Item 1 & .340 & .760 & -.038 & -.124 & -.120 & -.107 & -.146 & .300 & .338 & .741 & -.025 & -.120 & -.122 & -.102 & -.162 & .305 \\
\hline Item 2 & .366 & .790 & .197 & -.075 & -.131 & -.047 & -.109 & .235 & .359 & .760 & .127 & -.071 & -.132 & -.043 & -.120 & .232 \\
\hline Item 3 & .335 & .752 & -.142 & -.085 & -.115 & -.061 & -.296 & .263 & .337 & .742 & -.095 & -.084 & -.119 & -.059 & -.332 & .273 \\
\hline \multicolumn{17}{|l|}{ IDR } \\
\hline Item 1 & .644 & .204 & .008 & -.173 & -.031 & -.096 & -.122 & .477 & 638 & .198 & .005 & -.167 & -.032 & -.091 & -.134 & .481 \\
\hline Item 2 & .442 & .619 & .155 & -.085 & -.246 & -.026 & -.126 & .328 & .435 & .598 & .101 & -.081 & -.248 & -.024 & -.139 & .327 \\
\hline Item 3 & .508 & .302 & -.143 & .084 & -.144 & -.087 & -.104 & .560 & .511 & .298 & -.095 & .082 & -.149 & -.083 & -.117 & .582 \\
\hline \multicolumn{17}{|l|}{ INR } \\
\hline Item 1 & .788 & -.313 & -.157 & -.119 & .260 & -.019 & .011 & .386 & .789 & -.307 & -.104 & -.116 & .267 & -.018 & .012 & .398 \\
\hline Item 2 & 673 & .107 & .280 & -.038 & -.117 & .060 & .048 & .423 & .681 & .106 & .187 & -.037 & -.122 & .058 & .054 & .445 \\
\hline Item 3 & .255 & -.112 & -.046 & .685 & .183 & .021 & .109 & .211 & .254 & -.110 & -.031 & .663 & .187 & .020 & .121 & .215 \\
\hline Item 4 & .309 & -.118 & .007 & .675 & .059 & .125 & .103 & .250 & .312 & -.117 & .005 & .662 & .061 & .120 & .116 & .262 \\
\hline \multicolumn{17}{|l|}{ EXRS } \\
\hline Item 1 & .404 & -.144 & -.279 & -.077 & .628 & .052 & .052 & .391 & .391 & -.136 & -.179 & -.072 & .624 & .048 & .056 & .377 \\
\hline Item 2 & .317 & -.094 & .178 & .129 & .657 & .141 & .236 & .279 & .296 & -.086 & .110 & .117 & .629 & .125 & .245 & .249 \\
\hline Item 3 & .154 & -.094 & .147 & .291 & .557 & .130 & .340 & .216 & .141 & -.085 & .090 & .260 & .526 & .113 & .349 & .188 \\
\hline \multicolumn{17}{|l|}{ EXRM } \\
\hline Item 1 & .056 & -.109 & -.122 & .095 & .261 & .480 & .258 & .325 & .055 & -.104 & -.079 & .090 & .262 & .445 & .281 & .318 \\
\hline Item 2 & .254 & -.086 & .064 & .049 & .082 & .829 & -.015 & .272 & .252 & -.084 & .042 & .048 & .083 & .784 & -.016 & .276 \\
\hline Item 3 & .359 & .042 & .054 & .194 & -.051 & .179 & .027 & .754 & .354 & .041 & .035 & .186 & -.052 & .168 & .029 & .755 \\
\hline \multicolumn{17}{|l|}{ AMO } \\
\hline Item 1 & -.056 & -.186 & .191 & .082 & .191 & .054 & .848 & .217 & -.051 & -.166 & .115 & .072 & .178 & .047 & .861 & .185 \\
\hline Item 2 & -.071 & -.131 & .052 & .096 & .182 & .053 & .815 & .147 & -.064 & -.117 & .031 & .085 & .171 & .046 & .829 & .125 \\
\hline Item 3 & -.053 & -.123 & -.287 & .084 & .138 & .064 & .660 & .073 & -.049 & -.111 & -.174 & .075 & .130 & .056 & .677 & .170 \\
\hline$\omega$ & .870 & .869 & .006 & .644 & .795 & .621 & .925 & & .866 & .735 & .028 & .623 & .795 & .591 & .921 & \\
\hline
\end{tabular}

Note. $\mathrm{G}=$ global factor estimated as part of a bifactor model; $\mathrm{S}=$ specific factor estimated as part of a bifactor model; $\lambda$ : factor loading; $\delta$ : item uniqueness; $\omega$ : omega coefficient of model-based composite reliability; IM = intrinsic motivation; IDR = identified regulation; INR = introjected regulation; EXRS = external regulation-social; EXRM = external regulation-material; AMO = amotivation; non-significant parameters $(p \geq .05)$ are marked in italics. 


\section{Table S3}

Fully Invariant Standardized Factor Loadings $(\lambda)$ and Uniquenesses $(\delta)$ from the CFA Solution (Predictors)

\begin{tabular}{|c|c|c|c|c|c|}
\hline Items & $\begin{array}{c}\text { Mental load } \\
\lambda\end{array}$ & $\begin{array}{c}\text { Work load } \\
\lambda\end{array}$ & $\begin{array}{c}\text { Emotional load } \\
\lambda\end{array}$ & $\begin{array}{c}\text { Peer support } \\
\lambda\end{array}$ & $\delta$ \\
\hline \multicolumn{6}{|l|}{ Mental load } \\
\hline Item 1 & .815 & & & & .336 \\
\hline Item 2 & .780 & & & & .391 \\
\hline Item 3 & .805 & & & & .352 \\
\hline Item 4 & .851 & & & & .275 \\
\hline \multicolumn{6}{|l|}{ Work load } \\
\hline Item 1 & & .680 & & & .537 \\
\hline Item 2 & & .795 & & & .368 \\
\hline Item 3 & & .682 & & & .534 \\
\hline Item 4 & & .660 & & & .564 \\
\hline \multicolumn{6}{|c|}{ Emotional load } \\
\hline Item 1 & & & .761 & & .421 \\
\hline Item 2 & & & .597 & & .644 \\
\hline Item 3 & & & .663 & & .561 \\
\hline Item 4 & & & .646 & & .583 \\
\hline \multicolumn{6}{|l|}{ Peer support } \\
\hline Item 1 & & & & .893 & .203 \\
\hline Item 2 & & & & .943 & .110 \\
\hline Item 3 & & & & .803 & .356 \\
\hline Item 4 & & & & .874 & .236 \\
\hline$\omega$ & .886 & .798 & .763 & .932 & \\
\hline
\end{tabular}

Note. $\lambda$ : factor loading; $\delta$ : item uniqueness; $\omega$ : omega coefficient of model-based composite reliability. 
Table S4

Standardized Factor Loadings $(\lambda)$ and Uniquenesses $(\delta)$ from the CFA Solution (Outcomes)

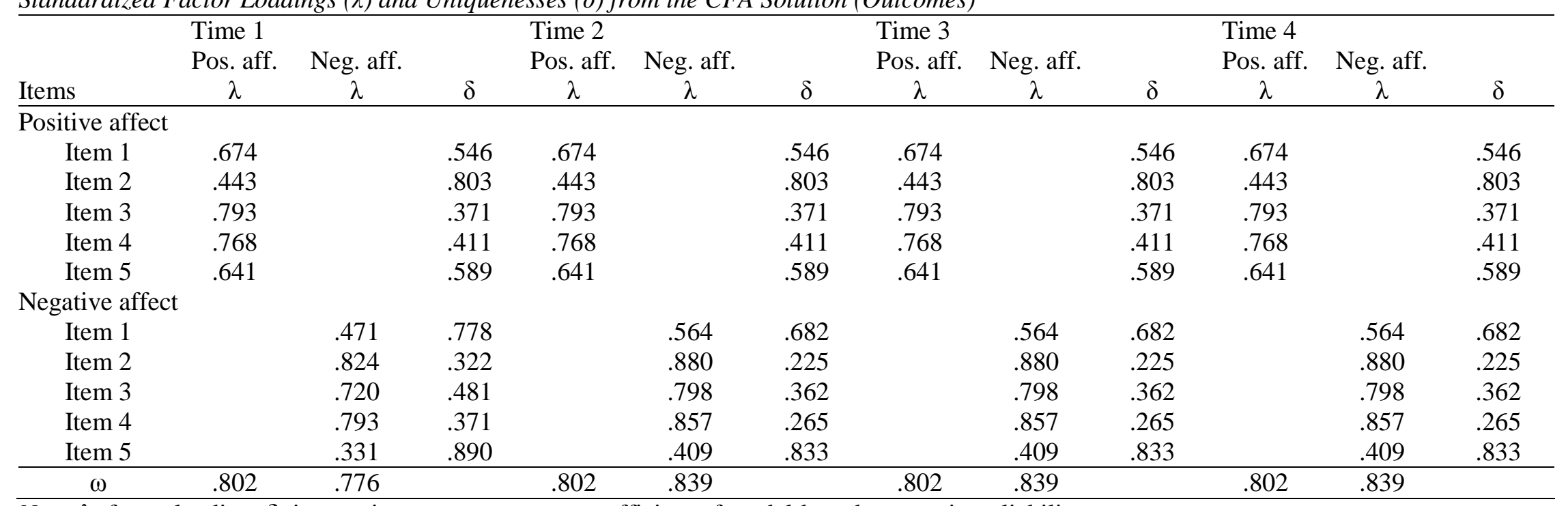

Note. $\lambda$ : factor loading; $\delta$ : item uniqueness; $\omega$ : omega coefficient of model-based composite reliability. 


\section{Appendix 2. A More Technical Presentation of Growth Mixture Analyses (GMA)}

GMA aim to represent longitudinal heterogeneity by the identification of subgroups (i.e., profiles) of participants following distinct trajectories. A quadratic GMA for the repeated measure $y_{i t}$ for individual $i$ at time $t$ is estimated within $k$ distinct levels $(\mathrm{k}=1,2, \ldots, \mathrm{K})$ of an unobserved latent categorical variable $c$ representing the profiles, with each individual having a probability $(p)$ of membership in the $k$ levels of this latent categorical variable.

$$
\begin{aligned}
& y_{i t}=\sum_{k=1}^{K} p_{k}\left[\alpha_{i y k}+\beta_{1 i y k} \lambda_{t}+\beta_{2 i y k} \lambda^{2}+\varepsilon_{y i t k}\right] \\
& \beta_{1 i y k}=\mu_{\beta 1 y k}+\zeta_{\beta 1 y i k} \\
& \beta_{2 i y k}=\mu_{\beta 2 y k}+\zeta_{\beta 2 y i k}
\end{aligned}
$$

The $k$ subscript indicates that most parameters can be freely estimated across profiles. In this equation, $\alpha_{i y k}, \beta_{1 i y k}$, and $\beta_{2 i y k}$ respectively represent the random intercept, random linear slope, and random quadratic slope of the trajectory for individual $i$ in profile $k ; \mu_{\alpha y k}, \mu_{\beta 1 y k}$, and $\mu_{\beta 2 y k}$ represent the average intercept, linear slope, and quadratic slope in profile $k$; and $\zeta_{\alpha y i k}, \zeta_{\beta 1 y i k}$ and $\zeta_{\beta 2 y i k}$ represent the variability of the intercept, linear slope, and quadratic slope across cases within profiles. $\varepsilon_{\text {yitk }}$ represents a diagonal matrix of time- individual- and class- specific residuals. $p_{k}$ defines the probability that an individual $i$ belongs to class $k$ with all $p_{k} \geq 0$ and $\sum_{k=1}^{K} p_{k}=1$. The variance parameters $\left(\zeta_{\text {ayik }}, \zeta_{\beta 1 \text { yik }}, \zeta_{\beta 2 y i k}\right.$ ) have a mean of zero and a $\Phi_{y k}$ variance-covariance matrix:

$$
\Phi_{y k}=\left[\begin{array}{ccc}
\psi_{\alpha \alpha y k} & & \\
\psi_{\alpha \beta 1 y k} & \psi_{\beta 1 \beta 1 y k} & \\
\psi_{\alpha \beta 2 y k} & \psi_{\beta 1 \beta 2 y k} & \psi_{\beta 2 \beta 2 y k}
\end{array}\right]
$$

In these models, Time is represented by $\lambda_{t}$, the factor loading matrix relating the time-specific indicators to the linear slope factor. The estimation of a quadratic slope factor simply involves the squaring o the time codes included in this factor loading matrix. Time is coded to reflect the passage of time and is thus a function of the intervals between measurement points. Given that the current study relies on four measurement points occurring 5,14, 25, and 41 weeks after the beginning of the training period, we decided to set the intercept at Time $1\left[E\left(\alpha_{i y k}\right)=\mu_{\mathrm{ylk}}\right]$, and to set the subsequent time codes to reflect the passage of time in months, leading to $\lambda_{1}=0, \lambda_{2}=2, \lambda_{3}=5$, and $\lambda_{4}=9$. As noted in the main manuscript, the current study relies on a more constrained estimation of GMA through which the latent variance-covariance matrix was specified as invariant across profiles, whereas the residuals were specified as freely estimated across profiles, leading to:

$$
\begin{aligned}
& y_{i t}=\sum_{k=1}^{K} p_{k}\left[\alpha_{i y k}+\beta_{1 i y k} \lambda_{t}+\beta_{2 i y k} \lambda^{2}+\varepsilon_{y i t k}\right] \\
& \beta_{1 i y k}=\mu_{\beta 1 y k}+\zeta_{\beta 1 y i} \\
& \beta_{2 i y k}=\mu_{\beta 2 y k}+\zeta_{\beta 2 y i}
\end{aligned}
$$


Supplements for Self-Determination Trajectories S12

$$
\Phi_{y}=\left[\begin{array}{ccc}
\psi_{\alpha \alpha y} & & \\
\psi_{\alpha \beta 1 y} & \psi_{\beta 1 \beta 1 y} & \\
\psi_{\alpha \beta 2 y} & \psi_{\beta 1 \beta 2 y} & \psi_{\beta 2 \beta 2 y}
\end{array}\right]
$$


Supplements for Self-Determination Trajectories S13

\section{Class Enumeration Process}

\section{Appendix 3. Optimal Model Selection}

A challenge in GMA is to determine the number of latent trajectory profiles in the data. Although the substantive meaning, theoretical conformity, and statistical adequacy of the solution are three critical elements to consider in this decision (Bauer \& Curran, 2003; Marsh, Lüdtke, Trautwein, \& Morin, 2009; Muthén, 2003), statistical indices support this decision (McLachlan \& Peel, 2000): (i) the Akaïke Information Criterion (AIC), (ii) the Consistent AIC (CAIC), (iii) the Bayesian Information Criterion (BIC), (iv) the sample-size Adjusted BIC (ABIC), (v) the standard and adjusted Lo, Mendel and Rubin's (2001) LRTs (LMR/aLMR, as these tests typically yield the same conclusions, we only report the aLMR); and (vi) the Bootstrap Likelihood Ratio Test (BLRT). A lower value on the AIC, CAIC, BIC, and ABIC suggests a better-fitting model. The aLMR and BLRT compare a $k$-profile model with a $k$ - 1 -profile model. A significant $p$ value indicates that the $k$-1-profile model should be rejected in favor of a $k$-profile model. Simulation studies indicate that four of these indicators (CAIC, BIC, ABIC, and BLRT) are particularly effective (e.g., Diallo, Morin, \& Lu, 2016, 2017; Nylund, Asparouhov, \& Muthén, 2007; Peugh \& Fan, 2013; Tein, Coxe, \& Cham, 2013; Tofighi \& Enders, 2008). In contrast, the AIC and LMR/ALMR should not be used in the class enumeration process as they respectively tend to over- and under-extract incorrect number of profiles. These indicators will be reported to ensure a complete disclosure, but will not be used to select the optimal number of profiles. These tests remain heavily influenced by sample size (Marsh et al., 2009). Indeed, with sufficiently large samples, they may keep on suggesting the addition of profiles without reaching a minimum. In these cases, information criteria should be graphically presented through "elbow plots" illustrating the gains associated with additional profiles (Morin, 2016; Morin et al., 2011). In these plots, the point after which the slope flattens suggests the optimal number of profiles. Finally, the entropy indicates the precision with which the cases are classified into the various profiles. The entropy should not be used to determine the optimal number of profiles (Lubke \& Muthén, 2007). However, summarizes classification accuracy ( 0 to 1 ), with higher values indicating more accuracy.

\section{Results: Optimal Number of Profiles}

The results from the unconditional GMA models are reported in the top section of Table S5 in these online supplements. The CAIC and BIC reached their lowest point for the 7-profile solution. However, the AIC, ABIC and BLRT keep on suggesting the addition of profiles, and the aLMR supports the 3-profile solution. To complement this information, we thus relied on the examination of an elbow plot, reported in Figure S1 of the online supplements. This plot showed that the improvement in fit flattened between the 2and 4-profile solutions. The examination of these alternative solutions showed that moving from a 2-profile solution to a 3-profile solution resulted in the addition of a well-defined qualitatively distinct and theoretically meaningful profile. However, moving from a 3-profile solution to a 4-profile solution simply resulted in the arbitrary division of one of the existing profile into two profiles differing only quantitatively from one another (i.e., this solution led to the identification of two very close average trajectory profiles showing only limited change over time). The 3-profile solution was thus retained, supporting Hypothesis 1. However, this solution converged on some improper parameter estimates (i.e., small negative variance estimates for the linear and quadratic slope factors). It suggests potential overparameterization (Bauer \& Curran, 2003; Chen, Bollen, Paxton, Curran, \& Kirby, 2001) due to the lack of significant within-profile variability on these two growth factors. To achieve proper estimation, these variance estimates (as well as covariances involving these slope factors) were constrained to be zero (Diallo et al., 2016). This constrained model was re-estimated, and converged on a proper solution. Supporting this solution, the CAIC and BIC showed further decreases compared with the model involving the free estimation of these parameters. Classification accuracy statistics are reported in Table S7 and reveal a very high level of accuracy ranging from .857 to .878 across profiles, which is consistent with the entropy value of .699 associated with this solution.

\section{Results: Optimal Predictive Model}

As recommended by Diallo et al. (2017; also see Morin, Meyer, Creusier, \& Biétry, 2016), the relative fit of the alternative control and predictor models was contrasted using the same information criteria already used in the present study (CAIC, BIC, and ABIC). A lower value indicates a better fit. The results related 
Supplements for Self-Determination Trajectories S14

to the models including the controls are reported in the middle section of Table S5, whereas those related to the models including the predictors are reported in the bottom section of Table S5. These results first support the null effects model for the controls, which resulted in the lowest CAIC, BIC, and ABIC values out of all models considered. For the predictors, the same indicators reached their lowest point for the model in which the predictors had an effect on the likelihood of profile membership, as well as a class-invariant effect on the initial levels of global self-determination.

\section{References used in this supplement}

Bauer, D.J., \& Curran, P.J. (2003). Distributional assumptions of growth mixture models over-extraction of latent trajectory classes. Psychological Methods, 8, 338-363.

Chen, F., Bollen, K.A., Paxton, P., Curran, P.J., \& Kirby, J. (2001). Improper solutions in structural models: Causes, consequences, strategies. Sociological Methods \& Research, 29, 468-508.

Diallo, T.M.O., Morin, A.J.S., \& Lu, H. (2016). Impact of misspecifications of the latent variancecovariance and residual matrices on the class enumeration accuracy of growth mixture models. Structural Equation Modeling, 23, 507-531.

Diallo, T.M.O., Morin, A.J.S., \& Lu, H. (2017). The impact of total and partial inclusion or exclusion of active and inactive time invariant covariates in growth mixture models. Psychological Methods, 22, 166-190.

Lo, Y., Mendell, N., \& Rubin, D. (2001). Testing the number of components in a normal mixture. Biometrika, 88, 767-778.

Lubke, G., \& Muthén, B. (2007). Performance of factor mixture models as a function of model size, criterion effects, and class specific parameters. Structural Equation Modeling, 14, 26-47.

Marsh, H.W., Lüdtke, O., Trautwein, U., \& Morin, A.J.S. (2009). Latent profile analysis of academic selfconcept dimensions: Synergy of person- and variable-centered approaches to the internal/external frame of reference model. Structural Equation Modeling, 16, 1-35.

McLachlan, G., \& Peel, D. (2000). Finite mixture models. New York: Wiley.

Morin, A.J.S. (2016). Person-centered research strategies in commitment research. In J.P. Meyer (Ed.), The handbook of employee commitment (pp. 490-508). Cheltenham, UK: Edward Elgar.

Morin, A.J.S., Maïano, C., Nagengast, B., Marsh, H.W., Morizot, J., \& Janosz, M. (2011). Growth mixture modeling of adolescents trajectories of anxiety: The impact of untested invariance assumptions on substantive interpretations. Structural Equation Modeling, 18, 613-648.

Morin, A.J.S., Meyer, J.P., Creusier, J., \& Biétry, F. (2016). Multiple-group analysis of similarity in latent profile solutions. Organizational Research Methods, 19, 231-254.

Muthén, B.O. (2003). Statistical and substantive checking in growth mixture modeling: Comment on Bauer and Curran (2003). Psychological Methods, 8, 369-377.

Nylund, K.L., Asparouhov, T., \& Muthén, B. (2007). Deciding on the number of classes in latent class analysis and growth mixture modeling. Structural Equation Modeling, 14, 535-569.

Peugh, J., \& Fan, X. (2013). Modeling unobserved heterogeneity using latent profile analysis: A Monte Carlo simulation. Structural Equation Modeling, 20, 616-639.

Tein, J.-Y., Coxe, S., \& Cham, H. (2013). Statistical power to detect the correct number of classes in latent profile analysis. Structural Equation Modeling, 20, 640-657.

Tofighi, D., \& Enders, C.K. (2008). Identifying the correct number of classes in growth mixture models. In G.R. Hancock \& K.M. Samuelsen (Eds.), Advances in latent variable mixture models (pp. 317-341). Charlotte, NC: Information Age. 


\section{0}

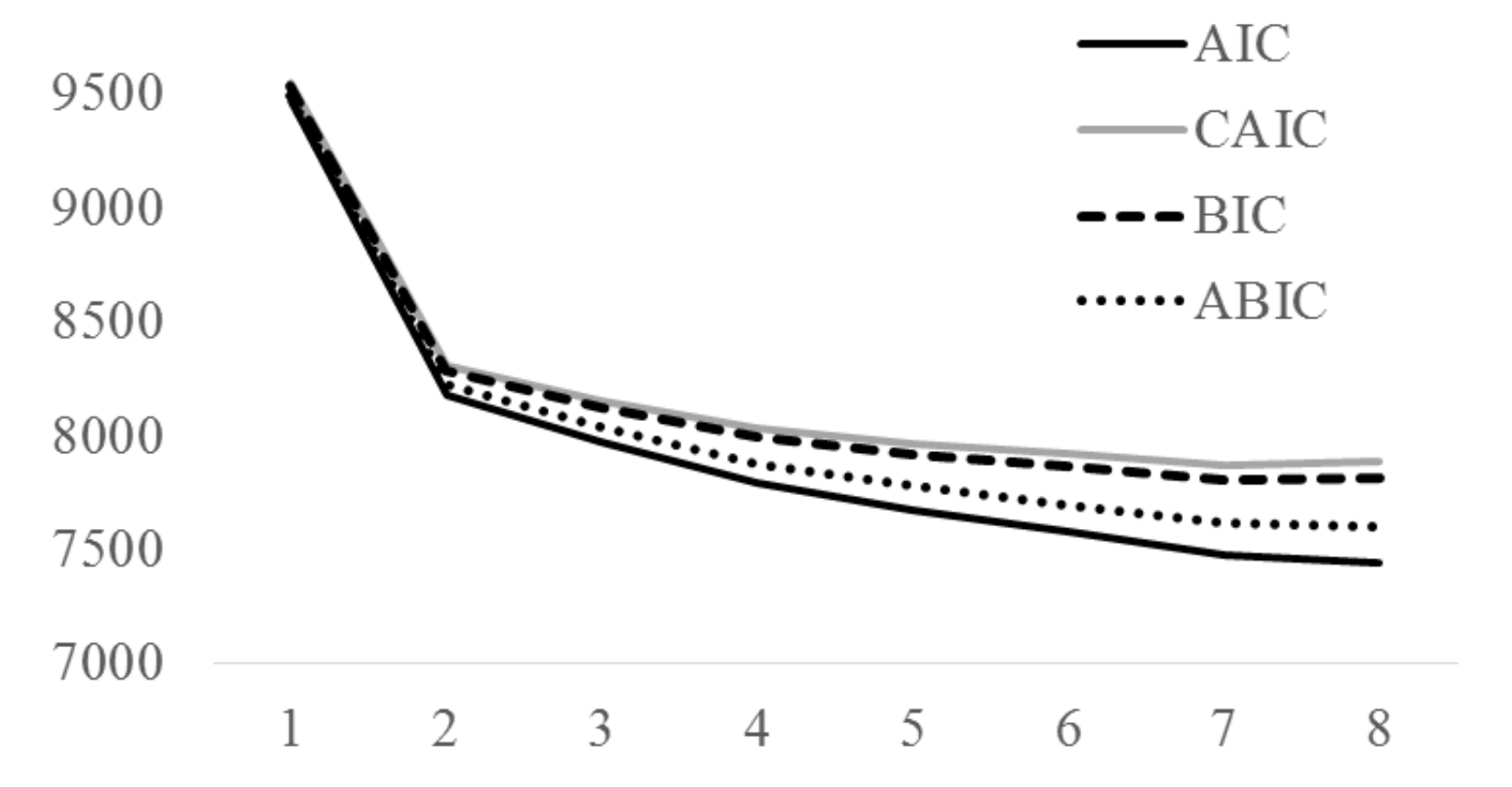

Figure S1

Elbow Plot of the Information Criteria for the Unconditional Growth Mixture Analyses 
Table S5

Fit Indices from Alternative Unconditional and Conditional Growth Mixture Analyses

\begin{tabular}{|c|c|c|c|c|c|c|c|c|c|c|}
\hline Model & $\mathrm{LL}$ & $\# f \mathrm{p}$ & SF & $\mathrm{AIC}$ & CAIC & $\mathrm{BIC}$ & $\mathrm{ABIC}$ & Entropy & aLMR & BLRT \\
\hline \multicolumn{11}{|l|}{ Unconditional Models } \\
\hline 1-Profile & -4719.451 & 13 & 2.032 & 9465.501 & 9548.883 & 9535.883 & 9494.584 & $\mathrm{Na}$ & $\mathrm{Na}$ & $\mathrm{Na}$ \\
\hline 2-Profile & -4065.254 & 21 & 1.611 & 8172.509 & 8307.202 & 8286.202 & 8219.489 & .607 & $<.001$ & $<.001$ \\
\hline 3-Profile & -3953.506 & 29 & 1.707 & 7965.013 & 8151.018 & 8122.018 & 8029.889 & .698 & $<.001$ & $<.001$ \\
\hline 4-Profile & -3857.739 & 37 & 1.406 & 7789.477 & 8026.794 & 7989.794 & 7872.251 & .685 & .240 & $<.001$ \\
\hline 5-Profile & -3791.453 & 45 & 1.312 & 7672.907 & 7961.535 & 7916.535 & 7773.577 & .609 & .240 & $<.001$ \\
\hline 6-Profile & -3734.221 & 53 & 1.368 & 7574.443 & 7914.383 & 7861.383 & 7693.010 & .625 & .240 & $<.001$ \\
\hline 7-Profile & -3675.940 & 61 & 1.380 & 7473.879 & 7865.131 & 7804.131 & 7610.344 & .645 & .240 & $<.001$ \\
\hline 8-Profile & -3651.665 & 69 & 1.489 & 7441.330 & 7883.894 & 7814.894 & 7595.691 & .645 & .240 & $<.001$ \\
\hline Final 3-Profile Solution & -3970.496 & 24 & 1.546 & 7988.992 & 8142.927 & 8118.927 & 8042.683 & .699 & $\mathrm{Na}$ & $\mathrm{Na}$ \\
\hline \multicolumn{11}{|c|}{ Conditional Models (Demographic Controls) } \\
\hline Null Effects Model & -3587.237 & 24 & 1.473 & 7222.473 & 7372.318 & 7348.318 & 7272.079 & .676 & $\mathrm{Na}$ & $\mathrm{Na}$ \\
\hline $\mathrm{P}->\mathrm{C}$ & -3578.736 & 30 & 1.381 & 7217.472 & 7404.777 & 7374.777 & 7279.478 & .677 & $\mathrm{Na}$ & $\mathrm{Na}$ \\
\hline $\mathrm{P}->\mathrm{C}$ and I (INV) & -3576.476 & 33 & 1.348 & 7218.952 & 7424.988 & 7391.988 & 7287.159 & .676 & $\mathrm{Na}$ & $\mathrm{Na}$ \\
\hline $\mathrm{P}->\mathrm{C}$ and $\mathrm{I}(\mathrm{VAR})$ & -3568.117 & 39 & 1.315 & 7214.234 & 7457.731 & 7418.731 & 7294.843 & .676 & $\mathrm{Na}$ & $\mathrm{Na}$ \\
\hline $\mathrm{P}->\mathrm{C}$ and I-S (INV) & -3571.321 & 36 & 1.335 & 7214.642 & 7439.409 & 7403.409 & 7289.050 & .673 & $\mathrm{Na}$ & $\mathrm{Na}$ \\
\hline $\mathrm{P}->\mathrm{C}$ and I-S (VAR) & -3558.151 & 48 & 1.260 & 7212.301 & 7511.99 & 7463.990 & 7311.512 & .676 & $\mathrm{Na}$ & $\mathrm{Na}$ \\
\hline $\mathrm{P}->\mathrm{C}$ and I-S-Q (INV) & -3570.918 & 39 & 1.316 & 7219.836 & 7463.333 & 7424.333 & 7300.445 & .974 & $\mathrm{Na}$ & $\mathrm{Na}$ \\
\hline$\underline{\mathrm{P}->\mathrm{C} \text { and } \mathrm{I}-\mathrm{S}-\mathrm{Q} \text { (VAR) }}$ & -3555.343 & 57 & 1.237 & 7224.686 & 7580.567 & 7523.567 & 7342.499 & .678 & $\mathrm{Na}$ & $\mathrm{Na}$ \\
\hline \multicolumn{11}{|c|}{ Conditional Models (Predictors) } \\
\hline Null Effects Model & -3945.853 & 24 & 1.540 & 7939.707 & 8093.322 & 8069.322 & 7993.078 & .697 & $\mathrm{Na}$ & $\mathrm{Na}$ \\
\hline $\mathrm{P}->\mathrm{C}$ & -3825.897 & 32 & 1.446 & 7715.793 & 7920.613 & 7888.613 & 7786.955 & .718 & $\mathrm{Na}$ & $\mathrm{Na}$ \\
\hline $\mathrm{P}->\mathrm{C}$ and $\mathrm{I}(\mathrm{INV})$ & 3758.951 & 36 & 1.394 & 7589.902 & 7816.325 & 7784.325 & 7669.959 & .706 & $\mathrm{Na}$ & $\mathrm{Na}$ \\
\hline P-> C and I (VAR) & -3749.327 & 44 & 1.368 & 7586.654 & 7868.281 & 7824.281 & 7684.500 & .709 & $\mathrm{Na}$ & $\mathrm{Na}$ \\
\hline $\mathrm{P}->\mathrm{C}$ and I-S (INV) & -3755.756 & 40 & 1.394 & 7591.512 & 7847.537 & 7807.537 & 7680.464 & .706 & $\mathrm{Na}$ & $\mathrm{Na}$ \\
\hline $\mathrm{P}->\mathrm{C}$ and $\mathrm{I}-\mathrm{S}$ (VAR) & -3738.749 & 56 & 1.388 & 7589.498 & 7947.933 & 7891.933 & 7714.030 & .710 & $\mathrm{Na}$ & $\mathrm{Na}$ \\
\hline $\mathrm{P}->\mathrm{C}$ and $\mathrm{I}-\mathrm{S}-\mathrm{Q}$ (INV) & -3750.935 & 44 & 1.378 & 7589.869 & 7871.497 & 7827.497 & 7687.716 & .706 & $\mathrm{Na}$ & $\mathrm{Na}$ \\
\hline P-> C and I-S-Q (VAR) & -3725.795 & 68 & 1.322 & 7587.591 & 8022.833 & 7954.833 & 7738.808 & .708 & $\mathrm{Na}$ & $\mathrm{Na}$ \\
\hline
\end{tabular}

Note . $\mathrm{LL}=$ model loglikelihood; $\# \mathrm{fp}=$ number of free parameters; $\mathrm{SF}=$ scaling correction factor; $\mathrm{AIC}=$ Akaike information criterion; $\mathrm{CAIC}=$ consistent AIC; BIC = Bayesian information criterion; ABIC = sample-size adjusted BIC; aLMR = Lo-Mendel and Rubin's likelihood ratio test; $\mathrm{BLRT}=$ bootstrap likelihood ratio test; $\mathrm{NA}=$ not applicable; $\mathrm{P}->=$ the predictors were allowed to influence; $\mathrm{C}=$ profile membership; $\mathrm{I}=$ intercept; $\mathrm{S}=$ linear slope; $\mathrm{Q}=$ quadratic slope; $\mathrm{INV}=$ prediction invariant across profiles; $\mathrm{VAR}=$ prediction varying across profiles. 


\section{Table S6}

Results from the Final Unconditional Three-Class Growth Mixture Analysis

\begin{tabular}{|c|c|c|c|}
\hline Parameter & $\begin{array}{l}\text { Profile } 1 \text { (Moderate) } \\
\text { Estimate }(t)\end{array}$ & $\begin{array}{l}\text { Profile 2(High) } \\
\text { Estimate }(t)\end{array}$ & $\begin{array}{l}\text { Profile } 3 \text { (Low) } \\
\text { Estimate }(t)\end{array}$ \\
\hline Intercept mean & $.007(.270)$ & $.558(13.425)^{* *}$ & $-.604(-8.446)^{* *}$ \\
\hline Linear slope mean & $-.035(-10.750) * *$ & $.087(6.101)^{* *}$ & $-.135(-7.655)^{* *}$ \\
\hline Quadratic slope mean & $.001(3.157)^{* *}$ & $-.010(-7.134)^{* *}$ & $.011(6.210)^{* *}$ \\
\hline Intercept variability $(S D=\sqrt{ } \sigma)$ & $.533(12.116)^{* *}$ & $.533(12.116)^{* *}$ & $.533(12.116)^{* *}$ \\
\hline Linear slope variability $(S D=\sqrt{ } \sigma)$ & 0 (Fixed) & 0 (Fixed) & 0 (Fixed) \\
\hline Quadratic slope variability $(S D=\sqrt{ } \sigma)$ & 0 (Fixed) & 0 (Fixed) & 0 (Fixed) \\
\hline$S D\left(\varepsilon_{y i l k}\right)$ & $.205(7.837)^{* *}$ & $.459(8.178)^{* *}$ & $.569(7.613)^{* *}$ \\
\hline$S D\left(\varepsilon_{y i 2 k}\right)$ & $.118(7.085)^{* *}$ & $.327(6.561)^{* *}$ & $.447(3.708)^{* *}$ \\
\hline$S D\left(\varepsilon_{y i 3 k}\right)$ & $.084(3.968)^{* *}$ & $.383(5.584)^{* *}$ & $.348(6.532)^{* *}$ \\
\hline$S D\left(\varepsilon_{y i 4 k}\right)$ & $.170(9.652)^{* *}$ & $.422(7.064)^{* *}$ & $.575(5.805)^{* *}$ \\
\hline
\end{tabular}

Note. $t=$ estimate / standard error of the estimate ( $t$ values are computed from original variance estimate and not from their square roots); $S D\left(\varepsilon_{y i t}\right)=$ standard deviations of the time-specific residuals; we present the square roots of the estimates of the variability so that these results can be interpreted units of the motivation factor scores at Time $1(M=0 ; S D=1) ; * p \leq .05 ; * * p \leq .01$.

Table S7

Classification Accuracy: Classification Probability for Most Likely Profile Membership (Column) as a Function of the Profile Membership (Row)

\begin{tabular}{lccc}
\hline & Profile 1 (Moderate) & Profile 2 (High) & Profile 3 (Low) \\
\hline Profile 1 (Moderate) & .878 & .076 & .046 \\
Profile 2 (High) & .068 & .872 & .060 \\
Profile 3 (Low) & .060 & .083 & .857 \\
\hline
\end{tabular}


Table S8

Time-Specific Associations between the Predictors and the Self-Determination Trajectories

\begin{tabular}{|c|c|c|c|c|}
\hline \multirow[b]{2}{*}{ Covariate Level } & \multicolumn{2}{|c|}{ Moderate (Profile 1)High (Profile 2) } & \multirow{2}{*}{$\begin{array}{l}\text { Low (Profile 3) } \\
\text { Mean (CI) }\end{array}$} & \multirow{2}{*}{$\begin{array}{l}\text { Summary of } \\
\text { Differences }\end{array}$} \\
\hline & Mean $(\mathrm{CI})$ & Mean $(\mathrm{CI})$ & & \\
\hline \multicolumn{5}{|l|}{ Mental Load } \\
\hline Time 1 & $-.104[-.157 ;-.051]$ & $.410[.359 ; .461]$ & $-.437[-.515 ;-.359]$ & $2>1>3$ \\
\hline Time 2 & $-.391[-.448 ;-.334]$ & $.249[.196 ; .302]$ & $-.710[-.794 ;-.626]$ & $2>1>3$ \\
\hline Time 3 & $-.570[-.627 ;-.513]$ & $.120[.067 ; .173]$ & $-.945[-1.035 ;-.855]$ & $2>1>3$ \\
\hline Time 4 & $-.724[-.775 ;-.673]$ & $-.136[-.189 ;-.083]$ & $-1.061[-1.141 ;-.981]$ & $2>1>3$ \\
\hline \multicolumn{5}{|l|}{ Work Load } \\
\hline Time 1 & $-.057[-.110 ;-.004]$ & $.209[.142 ; .276]$ & $-.355[-.429 ;-.281]$ & $2>1>3$ \\
\hline Time 2 & $-.059[-.112 ;-.006]$ & $.392[.323 ; .461]$ & $-.326[-.399 ;-.253]$ & $2>1>3$ \\
\hline Time 3 & $-.029[-.080 ; .022]$ & $.485[.416 ; .554]$ & $-.301[-.377 ;-.225]$ & $2>1>3$ \\
\hline Time 4 & $-.048[-.097 ; .001]$ & $.328[.265 ; .391]$ & $-.351[-.424 ;-.278]$ & $2>1>3$ \\
\hline \multicolumn{5}{|l|}{ Emotional Load } \\
\hline Time 1 & $-.028[-.079 ; .023]$ & $.104[.039 ; .169]$ & $-.328[-.402 ;-.254]$ & $2>1>3$ \\
\hline Time 2 & $-.038[-.091 ; .015]$ & $.240[.171 ; .309]$ & $-.330[-.403 ;-.257]$ & $2>1>3$ \\
\hline Time 3 & $.008[-.043 ; .059]$ & $.388[.319 ; .457]$ & $-.278[-.352 ;-.204]$ & $2>1>3$ \\
\hline Time 4 & $-.011[-.058 ; .036]$ & $.257[.194 ; .320]$ & $-.285[-.356 ;-.214]$ & $2>1>3$ \\
\hline \multicolumn{5}{|l|}{ Peer Support } \\
\hline Time 1 & $-.070[-.125 ;-.015]$ & $.286[.239 ; .333]$ & $-.254[-.344 ;-.164]$ & $2>1>3$ \\
\hline Time 2 & $-.254[-.315 ;-.193]$ & $.209[.158 ; .260]$ & $-.411[-.505 ;-.317]$ & $2>1>3$ \\
\hline Time 3 & $-.414[-.479 ;-.349]$ & $.077[.020 ; .134]$ & $-.647[-.753 ;-.541]$ & $2>1>3$ \\
\hline Time 4 & $-.510[-.571 ;-.449]$ & $-.088[-.145 ;-.031]$ & $-.725[-.821 ;-.629]$ & $2>1>3$ \\
\hline
\end{tabular}

Note. $\mathrm{CI}=95 \%$ confidence intervals; variables are estimated from factor scores with mean of 0 and a standard deviation of 1 at Time 1.

Table S9

Time-Specific Associations between the Outcomes and the Self-Determination Trajectories

\begin{tabular}{|c|c|c|c|c|}
\hline \multirow[b]{2}{*}{ Covariate Level } & \multicolumn{2}{|c|}{ Moderate (Profile 1)High (Profile 2) } & \multirow{2}{*}{$\begin{array}{l}\text { Low (Profile 3) } \\
\text { Mean (CI) }\end{array}$} & \multirow{2}{*}{$\begin{array}{l}\text { Summary of } \\
\text { Differences }\end{array}$} \\
\hline & Mean (CI) & Mean $(\mathrm{CI})$ & & \\
\hline \multicolumn{5}{|l|}{ Positive Affect } \\
\hline Time 1 & $.342[.289 ; .395]$ & $.299[.230 ; .368]$ & $.347[.271 ; .423]$ & $1=2=3$ \\
\hline Time 2 & $.036[-.019 ; .091]$ & $.059[-.010 ; .128]$ & $.024[-.056 ; .104]$ & $1=2=3$ \\
\hline Time 3 & $-.029[-.088 ; .030]$ & $-.025[-.098 ; .048]$ & $-.018[-.102 ; .066]$ & $1=2=3$ \\
\hline Time 4 & $-.049[-.102 ; .004]$ & $.007[-.060 ; .074]$ & $-.032[-.108 ; .044]$ & $1=2=3$ \\
\hline \multicolumn{5}{|l|}{ Negative Affect } \\
\hline Time 1 & $-.558[-.603 ;-.513]$ & $-.591[-.646 ;-.536]$ & $-.552[-.617 ;-.487]$ & $1=2=3$ \\
\hline Time 2 & $-.190[-.249 ;-.131]$ & $-.276[-.347 ;-.205]$ & $-.165[-.251 ;-.079]$ & $2>3 ; 1=2 ; 1=3$ \\
\hline Time 3 & $.022[-.037 ; .081]$ & $-.022[-.095 ; .051]$ & $.054[-.032 ; .140]$ & $1=2=3$ \\
\hline Time 4 & $.061[.006 ; .116]$ & $-.074[-.139 ;-.009]$ & $.018[-.058 ; .094]$ & $1>2 ; 1=3 ; 2=3$ \\
\hline
\end{tabular}

Note. CI $=95 \%$ confidence intervals; variables are estimated from factor scores with mean of 0 and a standard deviation of 1 at Time 4 . 
Appendix 4. Specific Motivation Factors: Supplementary Analyses

To further investigate the nature of the estimated growth profiles, we contrasted them on the basis of the time-specific S-factors. Specific levels of identified regulation were not considered in these analyses due to their low level of specificity and composite reliability once participants global levels of self-determination where considered (see Table S2). The results from these comparisons are reported in Table S10. It is important to keep in mind that, according to bifactor specifications, these S-factors were estimated to be uncorrelated with one another and with the G-Factor. Across time points, specific levels of intrinsic motivation were the highest in the High profile, followed by the Moderate profile, and then by the Low profile. Across time points, specific levels of introjected regulation were higher in the High profile than in the remaining profiles. However, differences between these remaining profiles changed over time. At Time 1, specific levels of introjected regulation were higher in the Low profile relative to the Moderate profile. This difference became non-significant at Time 2. Then, at Times 3 and 4, specific levels of introjected regulation were higher in the Moderate profile relative to the Low profile. Specific levels of external-social and external-material regulations did not differ across profiles at Time 1. However, these two aspects of external regulation showed well-differentiated associations with profile membership at the subsequent time points. At Time 2, specific levels of external-social regulation were the highest in the Low profile, followed by the Moderate profile, and then by the High profile. However, at Time 3, most of these differences disappeared, leaving only a higher level of external-social regulation in the Low profile relative to the High profile. No differences remained at Time 4. In contrast, specific levels of external-material regulation were higher in the Moderate profile than in the Low profile at Time 2, and higher in the High and Moderate profiles relative to the Low profile at Times 3 and 4. Finally, across all time points, specific levels of amotivation stayed higher in the Low and Moderate profiles than in the High profile. 
Table S10

Time-Specific Associations between the Specific Motivation Factors and the Self-Determination Trajectories

\begin{tabular}{|c|c|c|c|c|}
\hline Covariate Level & $\begin{array}{l}\text { Moderate (Profile 1) } \\
\text { Mean (CI) }\end{array}$ & $\begin{array}{l}\text { High (Profile 2) } \\
\text { Mean (CI) }\end{array}$ & $\begin{array}{l}\text { Low (Profile 3) } \\
\text { Mean (CI) }\end{array}$ & $\begin{array}{l}\text { Summary of } \\
\text { Differences }\end{array}$ \\
\hline \multicolumn{5}{|c|}{$\overline{\text { Intrinsic motivation (specific) }}$} \\
\hline Time 1 & $.002[-.049 ; .053]$ & $.130[.067 ; .193]$ & $-.188[-.272 ;-.104]$ & $2>1>3$ \\
\hline Time 2 & $-.302[-.359 ;-.245]$ & $-.141[-.212 ;-.070]$ & $-.489[-.583 ;-.395]$ & $2>1>3$ \\
\hline Time 3 & $-.398[-.443 ;-.353]$ & $.424[.351 ; .497]$ & $-1.625[-1.739 ;-1.511]$ & $2>1>3$ \\
\hline Time 4 & $-.443[-.482 ;-.404]$ & $.415[.342 ; .488]$ & $-1.541[-1.639 ;-1.443]$ & $2>1>3$ \\
\hline \multicolumn{5}{|c|}{ Introjected regulation (specific) } \\
\hline Time 1 & $-.120[-.167 ;-.073]$ & $.204[.131 ; .277]$ & $.001[-.072 ; .074]$ & $2>3>1$ \\
\hline Time 2 & $.164[.111 ; .217]$ & $.682[.600 ; .764]$ & $.101[.028 ; .174]$ & $2>1=3$ \\
\hline Time 3 & $.378[.329 ; .427]$ & $1.776[1.680 ; 1.872]$ & - $-.027[-.086 ; .032]$ & $2>1>3$ \\
\hline Time 4 & $.476[.421 ; .531]$ & $.896[.814 ; .978]$ & $.340[.264 ; .416]$ & $2>1>3$ \\
\hline \multicolumn{5}{|c|}{ Ext. social regulation (specific) } \\
\hline Time 1 & $-.010[-.059 ; .039]$ & $.001[-.062 ; .064]$ & $.020[-.053 ; .093]$ & $1=2=3$ \\
\hline Time 2 & $.128[.065 ; .191]$ & $.024[-.052 ; .100]$ & $.290[.198 ; .382]$ & $3>1>2$ \\
\hline Time 3 & $.317[.248 ; .386]$ & $.222[.138 ; .306]$ & $.354[.256 ; .452]$ & $3>2 ; 1=3 ; 1=2$ \\
\hline Time 4 & $.504[.435 ; .573]$ & $.541[.453 ; .629]$ & $.417[.319 ; .515]$ & $1=2=3$ \\
\hline \multicolumn{5}{|c|}{ Ext material regulation (specific) } \\
\hline Time 1 & $.018[-.035 ; .071]$ & $.022[-.047 ; .091]$ & $-.067[-.143 ; .009]$ & $1=2=3$ \\
\hline Time 2 & $.168[.113 ; .223]$ & $.111[.042 ; .180]$ & $.071[-.007 ; .149]$ & $1>3 ; 1=2 ; 2=3$ \\
\hline Time 3 & $.212[.153 ; .271]$ & $.223[.149 ; .297]$ & $.085[.001 ; .169]$ & $1=2>3$ \\
\hline Time 4 & $.286[.231 ; .341]$ & $.317[.248 ; .386]$ & $.121[.043 ; .199]$ & $1=2>3$ \\
\hline \multicolumn{5}{|l|}{ Amotivation (specific } \\
\hline Time 1 & $.015[-.038 ; .068]$ & $-.102[-.155 ;-.049]$ & $.102[.012 ; .192]$ & $1=3>2$ \\
\hline Time 2 & $.692[.588 ; .796]$ & $.330[.230 ; .430]$ & $.688[.541 ; .835]$ & $1=3>2$ \\
\hline Time 3 & $1.227[1.096 ; 1.35$ & ] $.826[.689 ; .963]$ & $1.247[1.059 ; 1.435]$ & $1=3>2$ \\
\hline Time 4 & $1.557[1.418 ; 1.696]$ & $11.147[1.004 ; 1.290]$ & $1.635[1.431 ; 1.839]$ & $1=3>2$ \\
\hline
\end{tabular}

Note. CI $=95 \%$ confidence intervals; variables are estimated from factor scores with mean of 0 and a standard deviation of 1 at Time 1. 